\title{
A REDE GLOBAL DE PRODUÇÃO AUTOMOTIVA: ESTRUTURA DE REDE E ESTRATÉGIAS CORPORATIVAS NO RIO DE JANEIRO, BRASIL ${ }^{1}$
}

\section{The global automotive production network: Network structure and corporate strategies in Rio de Janeiro, Brazil}

Rodrigo Salles Pereira dos Santos Prof. Adjunto do Depto de Sociologia e do PPGSA-UFRJ santosrodrigosp@gmail.com Artigo recebido em 12/05/2020 e aceito em 18/03/2021

DOI: $10.12957 /$ tamoios.2021.56600

\section{RESUMO}

No artigo apresento a estrutura e diversidade de agentes do segmento brasileiro da Rede Global de Produção Automotiva (RGPA), analisando as relações entre seus nós, assim como as estratégias corporativas e relações de trabalho nas firmas líderes que compõem o Polo Automotivo, localizado no Sul Fluminense. A análise é realizada combinando a abordagem das Redes Globais de Produção (RGPs) com a introdução de uma tipologia operacional da estratégia corporativa. Metodologicamente, o trabalho se apoia em revisão não sistemática sobre redes, RGPs, Corporações Transnacionais (CTNs) e setor automotivo, assim como mobiliza dados primários e, principalmente, secundários sobre CTNs automotivas e mercado de trabalho. Os resultados indicam que as transformações recentes na estrutura da RGPA no Brasil tendem a reforçar o poder das montadoras, em detrimento de firmas fornecedoras e trabalhadores, assim como explicitam a especificidade do país como centro-chave de produção e consumo automotivo. Também demonstram a diversidade do Polo Automotivo do Rio de Janeiro, o que explica os impactos socioeconômicos desiguais dessa estrutura para o desenvolvimento regional.

Palavras-chave: Rede global de produção (RGP); corporação transnacional (CTN); indústria automotiva; Brasil; Rio de Janeiro

\begin{abstract}
In the paper, I present the structure and diversity of actors in the Brazilian segment of the Global Automotive Production Network (GAPN), analyzing the relationships between its nodes, as well as the corporate strategies and work relations in the lead firms that make up the Automotive Pole located in the Southern region of the state of Rio de Janeiro. The analysis is carried out by combining the Global Production Networks (GPN) approach with the introduction of an operational typology of corporate strategy. Methodologically, the work is supported by a non-systematic review on networks, GPN, transnational corporations (TNCs) and the automotive sector, as well as mobilizing primary and, mainly, secondary data on automotive TNCs and the labor market. Results indicate that
\end{abstract}


recent changes in the GAPN structure in Brazil tend to reinforce automakers' power, to the detriment of suppliers and workers, as well as highlight the country's specificity as a production and consumption key center. They also show the diversity of the Automotive Pole of Rio de Janeiro, which explains the unequal socioeconomic impacts of this structure for regional development.

Keywords: Global production network (GPN); transnational corporation (TNC); automotive sector; Brazil; Rio de Janeiro

\section{Introdução}

Embora parcela importante da produção automotiva brasileira tenha sido exportada em 2019 - 14,5\% (428,2 mil) (ANFAVEA, 2020, p. 66), a Organização Mundial do Comércio (OMC) estima que "a maior parte dos produtores estrangeiros de automóveis no Brasil não integrou suas fábricas brasileiras nas cadeias de valor mundial", conservando o setor "protegido e voltado para o mercado interno" (MOREIRA, 2017).

No mundo, a demanda agregada por veículos se contraiu em anos recentes, mas seus efeitos têm sido mais prejudiciais ao Brasil, que se tornou o $8^{\circ}$ maior produtor em 2019, com quase 2,9 milhões de unidades e 3,0\% do total produzido (95,4 milhões de autoveículos) (ANFAVEA, 2020, p. 135). Comparativamente, o país ocupava a $7^{\text {a }}$ posição no ranking em 2013, com 3,7 milhões de unidades e 4,2\% da produção mundial (ANFAVEA, 2018, p. 139). No período, a integração ao mercado norte-americano permitiu ao México assumir a liderança na América Latina, passando a responder por $54,8 \%$ da produção no subcontinente, enquanto o Brasil possuía 38,6\% de participação (ANFAVEA, 2020, p. 137).

Em 2019, a produção acumulada nacional chegou a quase 87,5 milhões de unidades, incluindo máquinas agrícolas e rodoviárias (ANFAVEA, 2020, p. 7), enquanto a frota em operação atingiu 42,7 milhões em 2015, de modo que 1 em cada 4,8 habitantes dispunham de autoveículo (ANFAVEA, 2020, p. 134). Ademais, a capacidade instalada atual da indústria ultrapassa 5 milhões de unidades (ANFAVEA, 2018, p. 7), configurando enorme sobrecapacidade (MOREIRA, 2017).

No entanto, o setor permanece central para a economia nacional, participando com 3,0\% do Produto Interno Bruto (PIB) brasileiro em 2017, e sendo responsável por 18,0\% do PIB da indústria da transformação. Por sua vez, sua contribuição em termos de tributos diretos (IPI, PIS/Cofins, ICMS e IPVA) equivaleu a R\$ 65,6 bilhões em 2018 (ANFAVEA, 2020, p. 7).

O parque automotivo nacional contava com 26 fabricantes e 65 unidades industriais distribuídas por 10 estados e 43 municípios em 2019 (cf. Mapa 1). Os fabricantes de autopeças correspondiam a 473 unidades, enquanto havia 5.249 concessionárias em todo o país (ANFAVEA, 2020, p. 7). A indústria empregava cerca de 125,6 mil trabalhadores em 2019, sendo 85,5\% na produção de autoveículos (ANFAVEA, 2020, p. 36). A ANFAVEA (2020) estima que os empregos diretos e indiretos gerados cheguem a 1,3 milhão de pessoas.

Esse artigo analisa a conformação do segmento brasileiro da Rede Global de Produção Automotiva (RGPA) e uma de suas expressões localizadas, o Polo Automotivo do Rio de Janeiro, discutindo seus agentes - com foco nas firmas e trabalhadores - e estrutura a partir de uma análise compreensiva dos nós ${ }^{2}$ da rede e das estratégias 
corporativas das firmas líderes, com ênfase nas dimensões do investimento, mercado e relações de trabalho.

Metodologicamente, o trabalho se apoia em revisão de literatura não sistemática sobre redes, redes globais de produção (RGPs), Corporações Transnacionais (CTNs) e setor automotivo, mobilizando dados primários de observação direta e, principalmente, dados secundários sobre CTNs automotivas e mercado de trabalho, com ênfase na análise de documentos oficiais e dados estatísticos da Relação Anual de Informações Sociais (RAIS), do Ministério da Economia (ME). Nesse ínterim, a análise se baseia na delimitação metodológica da RGPA às atividades econômicas compreendidas em 17 subclasses da Classificação Nacional de Atividades Econômicas (CNAE).

O trabalho se subdivide em 4 seções, além da Introdução. Na seção seguinte, é apresentado seu arcabouço teórico, apoiado no modelo teórico-metodológico das RGPs e na discussão sobre CTNs e estratégia corporativa. As seções seguintes comportam, respetivamente, uma descrição analítica da RGPA e do segmento brasileiro da rede, e uma apreciação das estruturas e estratégias corporativas das CTNs automotivas instaladas no estado do Rio de Janeiro. A seção conclusiva sintetiza os principais argumentos e aponta caminhos de investigação futuros.

\section{Redes Globais de Produção, Corporações Transnacionais e Estratégia Corporativa}

A ideia de organização como "unidade social discreta", isto é, como subconjunto definido por um sistema de coordenação da ação social de tipo econômico e, portanto, por orientação estratégica, remete ao próprio desenvolvimento da teoria organizacional. Nesse paradigma, formas organizacionais são vistas como mecanismos de coordenação necessários diante de um "mundo externo imprevisível", ou seja, como soluções institucionais eficientes em condições de incerteza (DAVIS, 2005).

Definido stricto sensu como um mercado, no qual a organização se relaciona com outros agentes econômicos; ou de modo ampliado, sendo o setor um conjunto de relações centrado na firma, mas influenciado por agentes não econômicos, esse mundo incerto é caracterizado por relações de poder. Desse modo, formas organizacionais tendem a ser avaliadas em termos de redução de riscos e promoção de estabilidade (DAVIS, 2005, p. 478), fortalecendo a posição da firma no ambiente.

Em oposição às relações mercantis, formas hierárquicas verticalizadas constituíram a solução organizacional elementar para a promoção da estabilidade e o crescimento da firma ao longo do séc. XX (GEREFFI, 2005, p. 80). Especificamente, a corporação transnacional (CTN) sofisticou tais mecanismos (MORGAN, 2017), expandindo seu "poder para coordenar e controlar operações em mais de um país" (DICKEN, 2011, p. 110). A pretensão estabilizadora de mercados seria mesmo constitutiva da estrutura e estratégia organizacionais em sua fase corporativa (PIORE e SABEL, 1984, p. 50). 
Mapa 1. Densidade das Unidades Industriais da Rede Global de Produção Automotiva por estado, Brasil (2019).

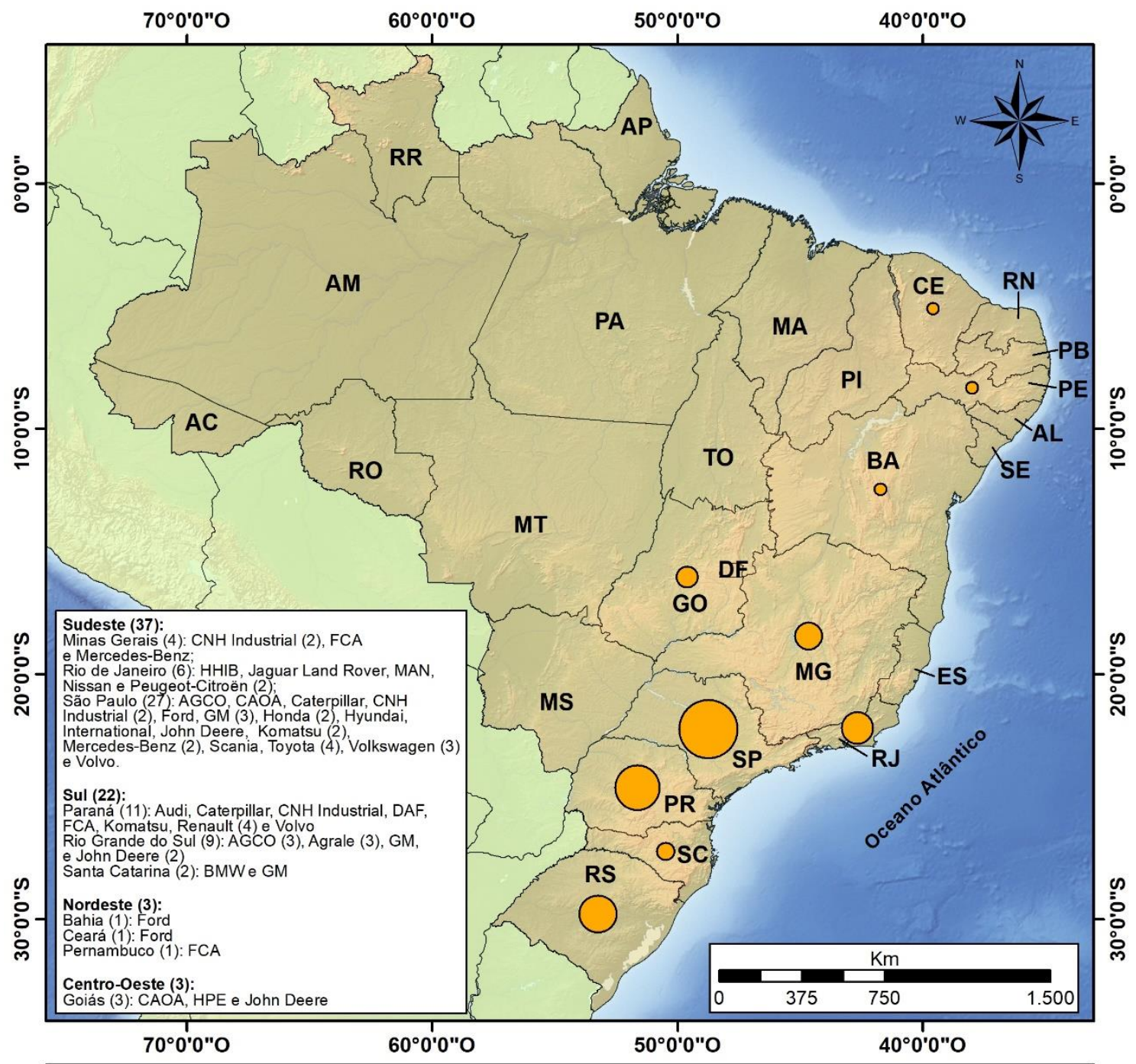

\section{LEGENDA: $\quad$ Quantidade de Plantas Automobilísticas por Estado:}

Brasil

América do Sul

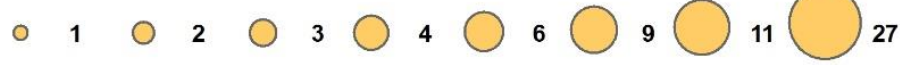

\section{Fontes:}

1 - Instituto Brasileiro de Geografia e Estatistica

(https://biblioteca.ibge.gov.br/) e (ftp://geoftp.ibge.gov.br/)

2 - Natural Earth Data (https://www.naturalearthdata.com/)

3 - Dados do Autor

Sistema de Coordenadas: SIRGAS 2000

Origem das Coordenadas: Equador e Meridiano de Greenwich Data: Dezembro/2020

Desenho: Waltencir Menon Junior - Geógrafo

Fonte: o autor, a partir de ANFAVEA (2020).

Essa definição de organização contribuiu para a generalização da firma como unidade analítica privilegiada (DAVIS, 2005), delimitando parâmetros teóricometodológicos e estratégias de investigação em estudos organizacionais e sobre trabalhadores. Entretanto, a transformação e diversificação das formas organizacionais a partir dos anos 1970 impôs um desafio considerável à coerência desses sistemas, dando 
origem a tentativas de registro em termos de trajetórias organizacionais, pós-fordismo, distritos industriais, toyotismo, redes verticais e horizontais, alianças corporativas e empresas-rede (CASTELLS, 1999), dentre outras.

Desde os anos 1980, abordagens centradas na noção de rede se tornaram centrais nas ciências humanas, em particular a partir da emergência da Nova Sociologia Econômica (NSE). A versão do argumento polanyiano do enraizamento da economia na sociedade a partir do "papel de relações pessoais concretas e estruturas" (GRANOVETTER, 1985, p. 490), permitiu uma inflexão, minando progressivamente a polarização entre organização e ambiente.

A teorização sobre organizações passou então a ser realizada a partir de limites interno-externo menos definidos e, portanto, permitiu a emergência de uma abordagem relacional que apreende as interações entre agentes econômicos e não econômicos como constitutiva da própria agência. Assim, CTNs passaram a ser concebidas como "redes dentro de redes, estruturadas através de uma miríade de relações, transações, trocas e interações complexas dentro de sua própria rede corporativa interna e entre essa rede e as dos outros atores-chave" (DICKEN, 2011, p. 121).

Assumindo a complexidade interna e externa da ação e relação sociais de tipo econômico em organizações, assim como a inadequação da forma organizacional como unidade de análise, é necessário, portanto, investigar o complexo de ações e relações que provêm realidade à $\mathrm{CTN}$ a partir de dois aportes.

Em primeiro lugar, CTNs perseguem fins concretos - market share, liderança industrial, crescimento, acesso a insumos, além de lucro (DICKEN, 2011, p. 110; GEREFFI, 2005, p. 165) - ao nível de Redes Globais de Produção (RGPs), isto é, no interior de complexos geograficamente dispersos e funcionalmente integrados "de funções e operações interligadas através das quais bens e serviços são produzidos, distribuídos e consumidos" (HENDERSON et al., 2011, p. 153).

A RGP constitui assim uma unidade analítica privilegiada para a investigação de processos econômicos globais. De um lado, remete a formas organizacionais que integram firmas e subconjuntos de suas atividades, assim como economias local-regionais e nacionais, representando interações de modo empiricamente adequado a partir da ideia de valor e seus processos. De outro, agrega agentes econômicos e não econômicos, explicitando as condições de efetivação da ação social de tipo econômico em termos de exercício do poder e de modos de enraizamento (HENDERSON et al., 2011).

No modelo, a busca de fins econômicos se orienta, no longo prazo, para a dimensão do valor, definido pela noção de mais-valia e pela centralidade do processo de trabalho, embora mediada por formas específicas de renda - tecnológicas, organizacionais, relacionais, de marca e de política comercial, em uma matriz processual que apreende sua criação, ampliação e captura (HENDERSON et al., 2011, p. 156).

Por sua vez, enquanto abordagens similares teorizaram o poder a partir de relações interfirma e estruturas de governança, a exemplo das cadeias de valor globais (GEREFFI, 2005), RGPs reconhecem a pluralidade das fontes de poder: corporativa, institucional e coletiva (HENDERSON et al., 2011, p. 157-8). Nesse sentido, o poder constitui uma propriedade relacional e assimétrica dos agentes, habilitando-os a influenciar consistentemente o comportamento de outros agentes em seu favor (SANTOS, 2011, p. 134).

Por fim, organizações constituem "formas específicas de relações sociais e, portanto, estão enraizadas em configurações sociais" (SANTOS, 2011, p. 136). Considerando o enraizamento como a "capacidade de influência das relações sociais lato sensu sobre a atividade econômica e seus agentes" (SANTOS, 2011, p. 136), é possível 
discernir nos estudos organizacionais enfoques centrados nas dimensões macroinstitucional, micropolítica e cognitiva, assim como na interdependência entre espaços sociais (HEIDENREICH, 2012).

A abordagem das RGPs exemplifica uma orientação macroinstitucional, enfatizando seja a herança sociocultural dos agentes econômicos - enraizamento social (HESS, 2004b), seja as diferentes formas de contextualização de sua ação (enraizamento territorial); ainda que o modelo confira relevo às relações interfirma, i.e., ao enraizamento de rede (HENDERSON et al., 2011, p. 160).

Em síntese, formas específicas de coordenação desempenhadas por CTNs sofrem a influência de um conjunto de variáveis condicionantes da ação e da racionalidade, de modo que padrões de enraizamento singulares e condições específicas de exercício de poder interagem com a capacidade de agência econômica orientada ao valor, produzindo consequências e resultados pouco previsíveis.

Não obstante integrar padrões de causalidade complexos, a CTN o faz em posição de relevância. Dessa forma, a despeito de seu condicionamento social e político, agentes corporativos transnacionais constituem casos liminares da busca consistente de fins econômicos racionalmente definidos, planejando e implementando com relativa coerência estratégias corporativas - ainda que possuam dimensão performática e discursiva (KNIGHTS e MORGAN, 1991).

É fundamental, portanto, compreender a CTN como "uma configuração estratégica de controle em processo contínuo de mudança, que combina o local e o global", entendida como uma coletividade de agentes "com diferentes estruturas" (HERNÁNDEZ, 2014, p. 53) ${ }^{3}$. Nesses termos, a estratégia corporativa ${ }^{4}$ é o resultado da definição e da execução racional e consistente de metas estabelecidas ao nível dos quadros superiores e de sua política de negócios, ainda que as condições de sua efetivação sejam determinadas politicamente e enraizadas socialmente.

Do ponto de vista da investigação empírica, é possível operacionaliza-la a partir de 5 dimensões específicas, com foco nas condições singulares de sua formulação e implementação diante de contextos econômicos, políticos e sociais condicionantes.

Assim, agentes econômicos se defrontam com questões relacionadas à obtenção dos recursos econômicos internos e externos e às formas de gestão interna destes recursos, constituindo estratégias de financiamento (EFs) (BENDER e WARD, 2009, p. 5). No que respeita às CTNs, a escala e diversidade geográfica e setorial de suas operações envolve maior dependência de recursos externos, induzindo formas variadas de obtenção e gerenciamento de recursos.

Por sua vez, a estratégia de investimento (EI) diz respeito à alocação de recursos disponíveis nos segmentos geográficos e setoriais nos quais a CTN opera e/ou planeja atuar. Remete, em grande medida, ao crescimento e à lucratividade de longo prazo, impactando a competitividade corrente e futura (CHEN e CHEN, 2010, p. 1). Entretanto, em contextos de retração de mercado e mudança organizacional e tecnológica, envolvem igualmente processos defensivos de desinvestimento, recentramento no core business, etc.

Estratégias de mercado (EMs) combinam um enfoque acerca dos principais bens e serviços ofertados pela organização e sua estrutura de comercialização, remetendo ao modo pelo qual a CTN se posiciona diante de competidores (ZOTT e AMIT, 2008, p. 3). Esses aspectos envolvem a descrição do core business e das formas organizacionais de acesso aos consumidores, o que remete a dificuldades de adaptação de instituições corporativas constituídas a partir de preferências do consumidor de base nacional. 
A estratégia tecnológica (ET), de outro lado, é definida como "o processo através do qual firmas utilizam seus recursos tecnológicos para atingir objetivos corporativos" (RIECK e DICKSON, 1993, p. 398). CTNs conectam diferentes trajetórias tecnológicas, que respondem à diversidade mutável do portfólio de bens e serviços que oferecem, se deparando com desafios de integração e coordenação de plataformas tecnológicas e de conformação de padrões de investimentos em pesquisa e desenvolvimento (P\&D).

Finalmente, a adoção de estratégias de relações de trabalho (ERTs) tem sido teorizada pela literatura organizacional já há algum tempo como ferramenta de prescrição do comportamento dos quadros gerenciais (MILLER, 1987). Entretanto, mesmo em suas representações normativas, a ERT tende a tomar em consideração.

[...] fatores contextuais, tais como força e atitudes de sindicatos e empregados, tamanho da firma, lucratividade, propriedade doméstica vs. estrangeira, formas de produção predominantes, níveis de habilidade, características da força de trabalho e a força das instituições do mercado de trabalho (ZHENG et al., 2007, p. 306).

Em resumo, a materialização de estratégias corporativas, ainda que formuladas no âmbito de sistemas cada vez mais eficientes de ação coletiva organizacional, constitui, necessariamente, um processo complexo, conflituoso e imprevisível, no qual intervêm agentes com capacidades assimétricas de exercício de poder, assim como estruturas de relações profundamente enraizadoras, que tanto restringem quanto tornam possível a ação organizacional e, portanto, a própria estratégia corporativa (HERNÁNDEZ, 2014, p. 4748).

A seção a seguir descreve e analisa a estrutura do segmento brasileiro da RGPA, privilegiando os condicionamentos subsetoriais da rede e refletindo sobre a diversidade e capacidades de influência dos agentes que a povoam.

\section{A RGP Automotiva}

\subsection{Aspectos gerais}

Veículos motorizados ou de autopropulsão são um subtipo de meios de transporte mecânicos terrestres, sendo movidos por combustão, podendo ser classificados em automóveis, caminhões e ônibus, e motocicletas. Considerando apenas os primeiros, é possível definir o automóvel típico como movido por motor de combustão interna, com propulsão por álcool, diesel e/ou, principalmente, gasolina.

No entanto, automóveis são uma mercadoria complexa e diversificada. Estima-se que montadoras lidem com "mais de dois mil componentes por produto final, com bilhões de combinações possíveis" (LIM, ALPAN e PENZ, 2014, p. 23), enquanto atributos materiais e simbólicos vinculados à autoimagem, liberdade de movimento e status social o caracterizam como um bem durável discricionário (DICKEN, 2007, p. 482) e, principalmente, um bem posicional (BUELL, 2011, p. 53).

Nesses termos, cadeias automotivas constituem arranjos intricados de agentes e instituições econômicas, cuja estrutura é representada como um conjunto de nós principais, cf. Figura 2.

\subsection{Engenharia}

Uma característica-chave dessa indústria é o elevado investimento em Pesquisa \& Desenvolvimento (P\&D) como proporção das inversões totais (CASTRO, BARROS e 
VAZ, 2014, p. 157). No Brasil, ainda que essa proporção flutue ao longo do tempo, o investimento em novos modelos de automóveis é imperativo, tendo em conta a centralidade da EM (ZOTT e AMIT, 2008) e o foco no produto. Assim, estima-se que "o investimento em P\&D das montadoras [no Brasil] situa-se frequentemente acima de $30 \%$ do investimento total" (CASTRO, BARROS e VAZ, 2014, p. 158).

As montadoras, firmas líderes de rede, são responsáveis pelos projetos de veículos (TORRES e CARIO, 2013, p. 78), embora, no Brasil, apenas algumas delas mantenham centros de engenharia "capazes de projetar um novo modelo de veículo desde a definição do conceito até a validação de produto e processo" (CASTRO, BARROS e VAZ, 2014, p. 159), responsáveis por automóveis como os novos Ka e Ecosport (Ford) e o Fox (Volkswagen).

Esses centros permanecem, grosso modo, situados nas matrizes, de modo que "a maior parte do esforço de engenharia continua concentrado em adaptações de modelos globais às condições locais [...] e em reestilizações" ". Esse padrão também caracteriza o "desenvolvimento de componentes e sistemas complexos ou disruptivos" (CASTRO, BARROS e VAZ, 2014, p. 160) por Original Equipment Manufacturers (OEM) ou grandes sistemistas em seus países-sede.

\subsection{Produção}

\subsubsection{Aspectos gerais}

Dados da International Organization of Motor Vehicle Manufacturers (OICA) indicam que a produção em 2019 atingiu 91,8 milhões de veículos, estando geograficamente concentrada. Nesses termos, a Ásia desponta soberana, com a China (25,7 milhões de unidades), Japão (9,7 milhões), Índia (4,5 milhões) e Coreia do Sul (4,0 milhões) respondendo por $28,0 \%, 10,6 \%, 4,9 \%$ e $4,3 \%$, respectivamente, da produção mundial. Se somam ao ranking, países europeus, como a Alemanha, que produziu 4,7 milhões $(5,1 \%)$, e Espanha, com 2,8 milhões de unidades $(3,1 \%)$; e polos como os Estados Unidos da América (EUA), que respondeu por 10,9 milhões (11,9\%), além de Brasil e México. Somados, os 20 maiores países produtores responderam por $93,1 \%$ da produção total em 2019, cf. Quadro 1 (OICA, 2020). 


\section{Figura 2. Diagrama da Rede Global de Produção Automotiva}

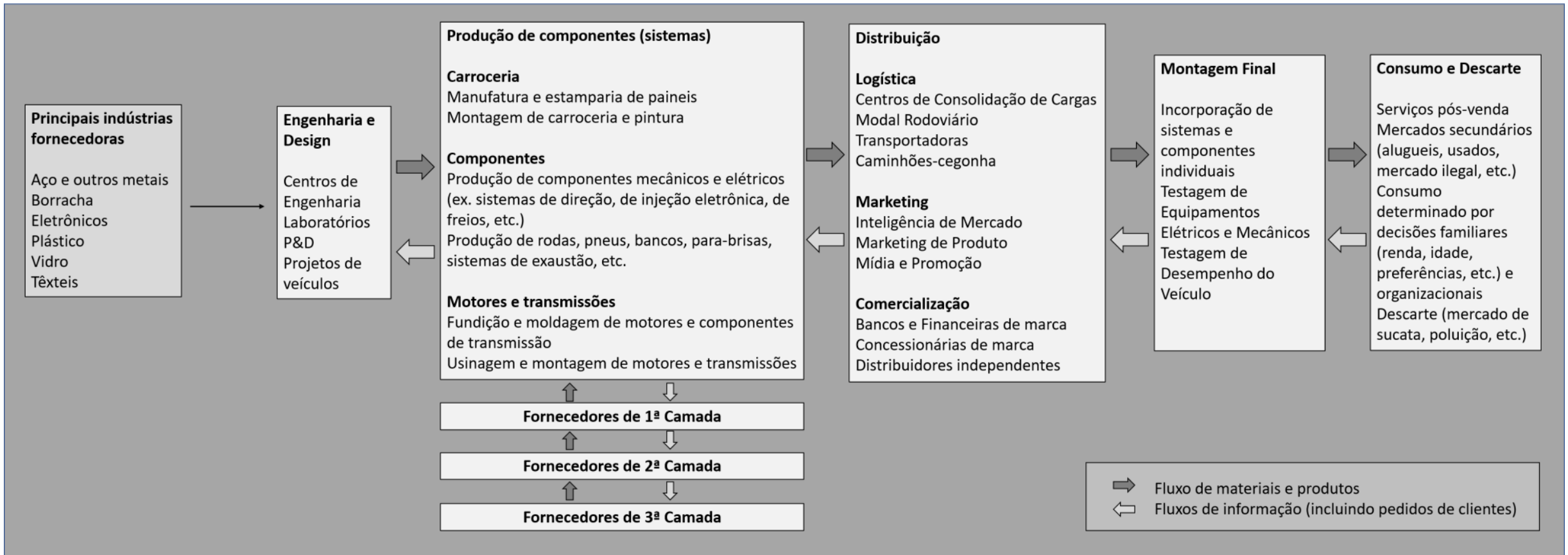

Fonte: o autor, adaptado de DICKEN (2007, p. 479). 
Quadro 1. 20 Maiores Produtores de Automóveis (2019)

\begin{tabular}{|c|c|c|c|c|c|c|c|}
\hline Posição & País & Automóveis & $\%$ & Veículos Comerciais & $\%$ & Veículos Totais & $\%$ \\
\hline 1 & China & 21360193 & 31,8 & 4360472 & 17,7 & 25720665 & 28,0 \\
\hline 2 & EUA & 2512780 & 3,7 & 8367239 & 34,0 & 10880019 & 11,9 \\
\hline 3 & Japão & 8328756 & 12,4 & 1355542 & 5,5 & 9684298 & 10,6 \\
\hline 4 & Alemanha & 4661328 & 6,9 & 0 & 0,0 & 4661328 & 5,1 \\
\hline 5 & Índia & 3623335 & 5,4 & 892682 & 3,6 & 4516017 & 4,9 \\
\hline 6 & México & 1382714 & 2,1 & 2604080 & 10,6 & 3986794 & 4,3 \\
\hline 7 & Coreia do Sul & 3612587 & 5,4 & 338030 & 1,4 & 3950617 & 4,3 \\
\hline 8 & Brasil & 2448490 & 3,6 & 496498 & 2,0 & 2944988 & 3,2 \\
\hline 9 & Espanha & 2248019 & 3,3 & 574336 & 2,3 & 2822355 & 3,1 \\
\hline 10 & França & 1675198 & 2,5 & 527262 & 2,1 & 2202460 & 2,4 \\
\hline 11 & Tailândia & 795254 & 1,2 & 1218456 & 4,9 & 2013710 & 2,2 \\
\hline 12 & Canadá & 461370 & 0,7 & 1455215 & 5,9 & 1916585 & 2,1 \\
\hline 13 & Rússia & 1523594 & 2,3 & 196190 & 0,8 & 1719784 & 1,9 \\
\hline 14 & Turquia & 982642 & 1,5 & 478602 & 1,9 & 1461244 & 1,6 \\
\hline 15 & Rep. Tcheca & 1427563 & 2,1 & 6400 & 0,0 & 1433963 & 1,6 \\
\hline 16 & Reino Unido & 1303135 & 1,9 & 78270 & 0,3 & 1381405 & 1,5 \\
\hline 17 & Indonésia & 1045666 & 1,6 & 241182 & 1,0 & 1286848 & 1,4 \\
\hline 18 & Eslováquia & 1100000 & 1,6 & 0 & 0,0 & 1100000 & 1,2 \\
\hline 19 & Itália & 542007 & 0,8 & 373298 & 1,5 & 915305 & 1,0 \\
\hline \multirow[t]{3}{*}{20} & Irã & 770000 & 1,1 & 51060 & 0,2 & 821060 & 0,9 \\
\hline & Total-20 & 61804631 & 92,0 & 23614814 & 95,8 & 85419445 & 93,1 \\
\hline & Total & 67149196 & 100,0 & 24637665 & 100,0 & 91786861 & 100,0 \\
\hline
\end{tabular}

Fonte: OICA (2020).

Segundo dados da Associação Nacional dos Fabricantes de Veículos Automotores (ANFAVEA), a produção nacional de veículos permanece concentrada no Sudeste, sendo São Paulo responsável 40,1\% da produção nacional, cf. Quadro 2. No entanto, os estados de Minas Gerais $(10,7 \%)$ e Rio de Janeiro $(6,7 \%)$, no Sudeste; do Paraná $(15,0 \%)$ e do Rio Grande do Sul (10,7\%), na região Sul; e da Bahia (7,5\%) e de Pernambuco $(7,5 \%)$, no Nordeste; além de Goiás (1,4\%), no Centro-Oeste, se tornaram importantes focos de inversão no setor desde os anos $1990^{6}$ (ANFAVEA, 2020, p. 52).

A RGPA se modificou drasticamente desde os anos 1990, com o aprofundamento de tendências à "redução do número de plataformas de veículos e de elevação de sua padronização, assim como de aceleração de seu ciclo de vida tecnológico, viabilizadas pela inovação da arquitetura modular" (DA COSTA e HENKIN, 2016, p. 463). Da perspectiva dos agentes econômicos, seu resultado mais expressivo remete à "ascensão de fornecedores globais", que se tornaram parceiros preferenciais nos processos de expansão geográfica das montadoras (TORRES e CARIO, 2013, p. 78).

Respondendo ao novo regime de governança, e pressionadas a se engajar diretamente nas EIs (CHEN e CHEN, 2010, p. 1) das montadoras, ávidas por partilhar custos fixos em plantas e em $\mathrm{P} \& \mathrm{D}$, os chamados mega suppliers ${ }^{7}$ dominaram a fabricação de sistemas complexos de componentes, compondo a primeira camada de estruturas complexas de fornecimento e chegando mesmo a coordenar a provisão "de peças e componentes de fornecedores de $2^{\circ}$ nível” (TORRES e CARIO, 2013, p. 79). Dessa 
forma, esses fornecedores "organizam redes de produção" per se, podendo "ser considerados como firmas líderes em relação à segunda e terceira camadas de fornecedores" (FRIGANT e ZUMPE, 2017, p. 6).

Quadro 2. Principais Estados e Municípios Produtores de Veículos (Brasil, 2019)

\begin{tabular}{|c|c|c|c|}
\hline Estado & Municípios e $\mathbf{N}^{\circ}$ de Unidades Fabris & Montadora & $\begin{array}{c}\% \\
\text { Prod. }\end{array}$ \\
\hline São Paulo & $\begin{array}{l}\text { Arujá, Indaiatuba (2), Iracemápolis, Itirapina, } \\
\text { Jacareí, Mogi das Cruzes (2), Pederneiras, } \\
\text { Piracicaba (3), Porto Feliz, São Bernardo do } \\
\text { Campo (4), São Caetano do Sul, São Carlos, São } \\
\text { José dos Campos, São Paulo, Sorocaba (2), } \\
\text { Sumaré, Suzano e Taubaté (2) }\end{array}$ & $\begin{array}{c}\text { Caoa, Ford, General Motors, } \\
\text { Honda, Hyundai, Mercedes- } \\
\text { Benz, Scania, Toyota, } \\
\text { Volkswagen }\end{array}$ & 40,1 \\
\hline Paraná & $\begin{array}{c}\text { Campo Largo (2), Curitiba (2), Pinhais, Ponta } \\
\text { Grossa e São José dos Pinhais (5) }\end{array}$ & $\begin{array}{l}\text { Audi, DAF, Renault, } \\
\text { Volkswagen, Volvo }\end{array}$ & 15,0 \\
\hline $\begin{array}{l}\text { Minas } \\
\text { Gerais }\end{array}$ & Betim, Contagem, Juiz de Fora e Sete Lagoas & FCA, Iveco, Mercedes-Benz & 10,7 \\
\hline $\begin{array}{l}\text { Rio Grande } \\
\text { do Sul }\end{array}$ & $\begin{array}{l}\text { Canoas, Caxias do Sul (3), Gravataí, } \\
\text { Horizontina, Ibirubá, Montenegro e Santa Rosa }\end{array}$ & Agrale, General Motors & 10,7 \\
\hline Bahia & Camaçari & Ford & 7,5 \\
\hline Pernambuco & Goiana & FCA & 7,5 \\
\hline $\begin{array}{l}\text { Rio de } \\
\text { Janeiro }\end{array}$ & Itatiaia (2), Porto Real (2) e Resende (2) & $\begin{array}{l}\text { Hyundai Heavy Industries, } \\
\text { Jaguar Land Rover, MAN, } \\
\text { Nissan, Peugeot Citroën }\end{array}$ & 6,7 \\
\hline Goiás & Anápolis e Catalão (2) & CAOA, HPE & 1,4 \\
\hline $\begin{array}{l}\text { Santa } \\
\text { Catarina }\end{array}$ & Araquari e Joinville & BMW & 0,3 \\
\hline Total & & & 99,9 \\
\hline
\end{tabular}

Fonte: ANFAVEA (2020, p. 52).

Assim, firmas líderes das RGPAs no Brasil reduziram drasticamente o número de fornecedores de primeira camada, tipicamente CTNs. A Renault, por exemplo, "possui 168 fornecedores, sendo 35 deles, $20 \%$ do total, classificados como de $1^{\circ}$ nível". Tais "fornecedores correspondem a 58\% da composição dos veículos produzidos" (TORRES e CARIO, 2013, p. 81).

Em seguida, se apresenta uma descrição tipificada das 4 principais etapas do processo de produção de veículos.

\subsubsection{Estamparia}

A seção de estamparia constitui o ponto de entrada do processo de produção automotivo, sendo o local no qual a montadora recebe e avalia a qualidade de bobinas de metal, oriundas de empresas siderúrgicas e/ou metalúrgicas, e as processa via corte para o processo programável de estampagem em prensas. As peças são então inspecionadas visualmente e, se aprovadas, seguem na linha de produção; as outras são selecionadas para retrabalho (CARVALHO, 2017; MOREIRA, 2014).

\subsubsection{Estruturação e Funilaria}

A estruturação diz respeito à armação de carrocerias, que envolve operações de funilaria tais como "soldagem, cravagem, grafagem, colagem, rebitagem e fixação com parafusos" (FERNANDES, 2009, p. 7), realizadas na seção de body shop. A carroceria 
consiste em um conjunto de "chapas e reforços metálicos, [qu]e define os espaços internos e as principais dimensões do veículo" (FERNANDES, 2009, p. 7). O processo se inicia com a identificação do novo veículo e a união de suas partes dianteira e lateral, se encerrando no acabamento. As operações são predominantemente robotizadas, com a soldagem de um automóvel envolvendo, por exemplo, 5 mil pontos (CARVALHO, 2017). O processo completo equivale a cerca de $1 / 3$ do tempo de fabricação e compreende, ainda, operações de testagem de portas, capôs e porta-malas, além de ajuste final e inspeção visual, realizadas por trabalhadores (CARVALHO, 2017).

\subsubsection{Pintura}

O acabamento externo do automóvel constitui requisito-chave de sua qualidade, sendo a pintura de carroceira um processo complexo, que responde por cerca de $10 \%$ do total de defeitos, afetando diretamente os resultados das montadoras (TREVIZAN, 2013, p. 3). Dessa forma, a pintura é também tipicamente robotizada. Sua primeira etapa corresponde ao pré-tratamento, envolvendo a limpeza da superfície de resíduos dos processos anteriores via imersão em tanques, jatos de água quente e desengraxantes. A etapa subsequente consiste na aplicação de uma primeira camada de tinta por adesão eletrostática com propriedades anti-corrosivas, o Elpo. Em seguida, o veículo passa por operações de secagem por "escorrimento de tinta, jatos de ar e estufa", além da remoção manual de defeitos com lixadeiras pneumáticas (TREVIZAN, 2013, p. 3). O processo posterior é o de vedação da unidade ou calafetação, prevenindo infiltrações. A quinta operação é a aplicação de tinta primer, que dá coloração e oferece proteção anti-corrosão. Após nova operação de lixamento, a unidade recebe aplicação de base e verniz (top coat) (TREVIZAN, 2013, p. 3), que dá coloração próxima à final (CARVALHO, 2017) à carroceria. Após a secagem em estufa, a unidade segue para a área de finesse, recebendo polimento e retoques finais (TREVIZAN, 2013, p. 3).

\subsubsection{Montagem Final}

Seguindo processo independente, as portas recebem "o acabamento com vidro, maçaneta, fiação elétrica, retrovisor e revestimento" (CARVALHO, 2017). Somente após a incorporação de "assentos, painel de instrumentos, vidros laterais e dianteiros e acabamento do teto e do interior" (CARVALHO, 2017), são integradas manualmente à unidade. $\mathrm{O}$ motor também segue trajetória independente, sendo testado previamente à instalação manual na carroceria. Em geral, a produção de motores é realizada internamente ou em unidade de produção conexa (CARVALHO, 2017).

$\mathrm{O}$ processo de montagem final diz respeito à incorporação dos demais componentes internos e externos do veículo: "quadros de instrumentos, carpetes, estofamentos laterais, bancos, para-brisas e elementos elétricos" (CARVALHO, 2017). Mais importante, é na montagem final que o conjunto de motor e transmissão é integrado à carroceria, além da instalação de rodas e pneus. Nessa etapa, a participação dos trabalhadores é mais expressiva (CARVALHO, 2017).

Após a montagem, os equipamentos elétricos e mecânicos são testados, além de outros indicadores, assim como o desempenho da unidade é avaliado em pistas de testes internas às fábricas.

\subsection{Distribuição}

\subsubsection{Logística}

Em detrimento das operações de logística interna, essa seção analisa as relações em rede para a distribuição de veículos no Brasil. Tipicamente, a distribuição no país 
ocorre por meio de transporte rodoviário, de modo que os veículos oriundos das montadoras são "recebidos num centro de consolidação de cargas" (BONASSA, 2018, p. 8), sendo transportados até as concessionárias.

Em 2011, uma decisão do Supremo Tribunal Federal (STF) permitiu às montadoras incorporar os custos de frete rodoviário, até então sob responsabilidade das concessionárias e calculado sobre a unidade veicular e repassado ao cliente (BONASSA, 2018 , p. 1). Ao tornar o pagamento fixo, calculado por quilometragem e pelo tamanho do veículo (BONASSA, 2018, p. 1), as firmas líderes subtraíram às transportadoras especializadas a capacidade de formação autônoma de preços em relação aos clientes (concessionárias), exercendo poder corporativo (HENDERSON et al., 2011, p. 157) em favor da redução de custos (BONASSA, 2018, p. 1).

Entre elas e os clientes finais, se interpõem, ainda, outros agentes, visto que "as transportadoras [...] terceirizam os serviços de transporte aos proprietários de caminhões cegonha" (BONASSA, 2018, p. 1), organizados, por sua vez, em associações. Nacionalmente $^{8}$, a principal organização de representação é o Sindicato Nacional dos Cegonheiros (SINACEG), cuja criação remonta aos anos 1980 (SINACEG, 2018).

\subsubsection{Marketing}

Concepções tradicionais do papel do marketing como etapa à jusante da produção na RGPA vêm sendo desafiadas por achados empíricos recentes. Em CTNs automotivas como a MAN Latin America, montadora de ônibus e caminhões em Resende (RJ), o processo de lançamento de um produto é, essencialmente, dependente do marketing (MAGGI, 2018, p. 80). Assim, um veículo MAN tem origem no Marketing de Produto, se apoiando em dados sobre demanda coletados pela Inteligência de Mercado. A primeira subárea da Gerência de Marketing é, portanto, a responsável pela concepção do veículo, encaminhando-o ao setor de Engenharia, cuja função é avaliar a viabilidade financeira e estabelecer os parâmetros do novo produto (o design), que serão reavaliados pelo Marketing de Produto (MAGGI, 2018, p. 80).

Dessa forma, cada vez mais as operações relacionadas ao marketing se movem upstream na rede automotiva, estando intimamente vinculadas às atividades de $\mathrm{P} \& \mathrm{D}$, design e engenharia. Nesses termos, uma RGPA depende, cada vez mais, das condições da demanda e preferências do consumidor. Ademais, a própria representação do marketing como elo de uma cadeia torna-se problemática, considerando a dinâmica de retroalimentação entre essa área e a de engenharia, apontada por MAGGI (2018) no caso da MAN Latin America. A forma assumida pelas interações entre as duas áreas em uma CTN automotiva se expressa como fluxos em rede (HENDERSON et al., 2011), dadas sua complexidade e condicionamento mútuo.

\subsubsection{Comercialização}

\subsubsection{Bancos e Financeiras}

O financiamento do veículo é um componente cada vez mais importante da RGPA, de maneira que "o banco da montadora" (PIERITZ, 2007) aparece como intermediário-chave da realização da mercadoria. Assim, não apenas atividades e operações financeiras integram RGPs automotivas, como suas firmas líderes buscam controla-las cada vez mais "através da constituição de bancos [e outros organismos financeiros] próprios" (SANTOS, 2005, p. 19). No Brasil, o formato organizacional se encontra consolidado, e as instituições financeiras vinculadas a montadoras se organizam sob a Associação Nacional das Empresas Financeiras das Montadoras (ANEF). 
Subsidiárias financeiras de montadoras têm como objetivo prover financiamento a fornecedores, concessionárias e clientes finais, o que explicita a amplitude de suas formas de captura de valor (HENDERSON et al., 2011, p. 156-157). A análise aqui proposta enfoca, no entanto, a relação banco-cliente a partir da oferta de crédito direto, operações de leasing e consórcio, etc. Abrangendo, ainda, mecanismos de "seguro de automóveis, contratos de manutenção, assistência em caso de acidente etc." (SANTOS, 2005 , p. 20), as montadoras se engajam ativamente em processos de ampliação de valor (HENDERSON et al., 2011, p. 156), agregando pacotes de serviços sob demanda.

$\mathrm{O}$ financiamento de veículos tem crescido no país, em detrimento da aquisição à vista, com preferência para o crédito direto ao consumidor (CDC) e para o consórcio. Nesse contexto, os consumidores brasileiros têm explicitado sua preferência pelas instituições financeiras vinculadas a montadoras, firmando até $60 \%$ dos contratos de CDC junto a essas organizações (SANTOS, 2005, p. 24).

\subsubsection{Concessionárias}

A comercialização de veículos no varejo é realizada, no Brasil, predominantemente por meio de concessionárias de marca ${ }^{9}$, sendo essas decisivas na conformação das EMs (ZOTT e AMIT, 2008) das montadoras. Dessa forma, havia 5.249 concessionárias em operação no Brasil em 2019 (ANFAVEA, 2020, p. 7), sendo 3.980 de autoveículos $(75,8 \%)$ e 1.269 de máquinas agrícolas e rodoviárias $(24,2 \%)$ (ANFAVEA, 2020, p. 30-32). No primeiro grupo, despontavam as concessionárias vinculadas a FCA $(16,1 \%)$, a Volkswagen e MAN $(12,9 \%)$, a General Motors $(9,0 \%)$ e a Ford (8,3\%); enquanto no segundo bloco se destacavam as concessionárias das marcas CNH Industrial (34,8\%), AGCO, Massey Ferguson e Valtra (29,7\%) e John Deere $(21,2 \%)$.

Estima-se que a totalidade da rede de concessionárias de marca é subcontratada, como nos casos da aliança Nissan-Renault-Mitsubishi (TORRES, 2011, p. 151). A relação entre montadora e concessionária é, assim, tipicamente contratual (PIERITZ, 2007, p. 2), sendo definida pelo poder corporativo (HENDERSON et al., 2011, p. 157) da primeira. Sua expressão mais relevante remete à formação do preço final do veículo, "facultando ao concessionário acréscimos como frete, pintura especial ou opcionais [...] solicitados pelo cliente" (PIERITZ, 2007, p. 2), e comprimindo suas margens de lucro (TORRES, 2011, p. 150).

As concessionárias se distribuem desigualmente, respondendo, em grande medida, à dimensão dos diferentes mercados regionais e estaduais. Dessa forma, 40,1\% de todas as concessionárias de marca se localiza na região Sudeste, seguida pelas regiões Sul $(26,3 \%)$ e Nordeste $(14,9 \%)$, Centro-Oeste $(12,0 \%)$ e Norte $(6,8 \%)$. Na primeira região, a concentração é ainda maior, com São Paulo respondendo por $56,1 \%$ das unidades, seguido por Minas Gerais $(24,3 \%)$, Rio de Janeiro $(14,5 \%)$ e, finalmente, Espírito Santo (5,2\%) (ANFAVEA, 2020, p. 30-32).

Em âmbito estadual, cerca de 500 firmas (SINCODIV-RJ, 2018) são representadas pelo Sindicato dos Concessionários e Distribuidores de Veículos Automotores do Estado do Rio de Janeiro (SINCODIV/RJ).

\subsection{Consumo}

\subsubsection{Serviços de pós-venda}

Cada vez mais, a relação entre montadora e cliente não se esgota na aquisição do produto, se estendendo através da mediação de outros agentes, em particular, as concessionárias, e de relações econômicas, i.e., os chamados serviços de pós-venda. No 
caso dos veículos de passeio, essa tendência se vincula à diferenciação de produto, mas é na comercialização de bens de capital, como caminhões e ônibus, que se observa "uma forte dependência" (SANT'ANNA, 2004, p. 86) dessas atividades.

Os serviços de pós-venda representam o conjunto "de operações de atendimento, de venda de peças e serviços decorrente da reparação dos veículos [....] e de relacionamento contínuo" (SOUZA, 2017, p. 19). Estima-se que contribuam com quase a metade das receitas "na indústria de produtos novos (automotivo, eletrônicos, computadores)" na Europa, assim como com mais de 1/3 das receitas da indústria no Brasil (SOUZA, 2017, p. 11).

Não é surpreendente, tendo em conta sua contribuição para os processos de ampliação de valor (HENDERSON et al., 2011, p. 156) em RGPAs, que as montadoras influenciem sua oferta. De um lado, nos serviços em garantia, os preços são determinados pelas firmas líderes, independentemente da concessionária, como forma de evitar sua captura. De outro, nos serviços fora da garantia, tipicamente de manutenção, e custeados pelo cliente final, é a concessionária a formadora de preços (PIERITZ, 2007, p. 13).

\subsubsection{Mercados secundários}

\subsubsection{Mercado de usados}

O carro usado representa um bem substituto influente na estrutura do subsetor automobilístico (ALVES, 2016, p. 21), sendo necessário considerar a composição do mercado secundário de veículos no país. Assim, a frota nacional em circulação superava 58,0 milhões de automóveis em 2019, com idade média de 15,2 anos (FENABRAVE, 2020 , p. 28), conformando um mercado de revenda extremamente importante (ALVES, 2016, p. 22).

Segundo a Federação Nacional da Distribuição de Veículos Automotores (FENABRAVE), o mercado de usados era 4,2 vezes maior que o de veículos novos em $2019^{10}$ (FENABRAVE, 2020, p. 28), culminando tendência de alta desde o início dos anos 2010. Automóveis usados com até 10 anos de uso correspondiam, assim, a 57,6\% do volume total de veículos usados transacionados no país (FENABRAVE, 2020, p. 28). Nesses termos, relações socioeconômicas mais amplas, nesse caso remetendo à distribuição de renda e à capacidade de consumo, desempenham um papel crucial no enraizamento territorial (HENDERSON et al., 2011, p. 160) das estratégias corporativas no setor.

Enquanto no Rio de Janeiro, as revendedoras da automóveis usados são representadas pela Associação das Agências de Veículos Usados do Rio de Janeiro (AAVURJ), em escala nacional é a Federação Nacional das Associações dos Revendedores de Veículos Automotores (FENAUTO) que realiza esse papel (FENAUTO, 2018).

\subsubsection{Mercado ilegal}

É difícil estimar o volume de roubos de veículos no país, em razão da precariedade de dados em escala nacional. No entanto, no estado do Rio de Janeiro foram roubados 666,2 mil veículos entre 1991 e 2015. Apenas nesse último ano, 31,0 mil veículos foram roubados, chegando a uma média de 2,6 mil roubos ${ }^{11}$ por mês.

Diante da forte correlação negativa entre o ingresso de novos carros em circulação no estado e o número de roubos anuais (ISP, 2016, p. 9), é razoável supor que a demanda por peças de reposição, parcialmente atendida pela indústria formal, é estruturante de um mercado secundário estadual de veículos roubados ${ }^{12}$, caracterizado pela presença de 
ferros-velhos ilegais e 'desmanches' (LEITÃO, 2013). Estima-se que existam cerca de 500 ferros-velhos clandestinos em operação no estado (GOULART, 2018).

Em escalas estadual e mesmo federal, a violência urbana se apresenta como fenômeno responsável, ainda que parcial e indiretamente, por dinâmicas econômicas da RGPA. A despeito de alguma, embora aparentemente tênue, conexão entre os mercados ilegal e legal (ABDALA, 2017), o primeiro produz efeitos econômicos e sociopolíticos em mercados do último tipo, como os de seguro de automóveis, e de alarmes e outros dispositivos de segurança - em geral, positivos; e o mercado formal de autopeças para reposição, em grande medida, negativos (FELTRAN e HORTA, 2019). Tais dinâmicas apontam novamente para a centralidade dos processos de enraizamento territorial (HENDERSON et al., 2011, p. 160) dessa rede.

\subsubsection{Descarte}

Autores como HEROD et al. (2013) enfocam o descarte de bens como automóveis como um nó-chave na conformação do processo de trabalho em RGPs. No caso da indústria automotiva, duas atividades principais caracterizam "o processamento de carros usados para sucata" (HEROD et al., 2013, p. 432). A primeira diz respeito ao desmantelamento de veículos em fim de vida (end of life vehicles, ELVs), voltando-se à recuperação de autopeças para revenda e remanufatura, que abrange cerca de $15 \mathrm{mil}$ unidades nos EUA (HEROD et al., 2013, p. 432). Por sua vez, o material remanescente deve passar por um processo de trituração, "sendo os metais ferrosos normalmente separados com o emprego de imãs, enquanto os não ferrosos [...] recuperados por meio de separadores de contracorrente" (HEROD et al., 2013, p. 433). Em especial, os metais ferrosos ${ }^{13}$ recuperados são amplamente utilizados como sucata de alta qualidade em usinas siderúrgicas semi-integradas, como as do grupo Arcelor Mittal, localizadas em Barra Mansa e Resende (RJ) - ingressando, dessa forma, em outras RGPs.

O processo de descarte de usados é, não obstante, influenciado pelo Estado que, ao exercer poder institucional (HENDERSON et al., 2011, p. 157-158) sobre as firmas líderes de RGPAs, através da imposição de padrões de emissão de poluentes atmosféricos, de taxação sobre emissão de $\mathrm{CO}_{2}$ e consumo extra de combustível, assim como de programas específicos de substituição de veículos (ALVES, 2016, p. 82), por exemplo, dinamiza os mercados primário e secundário de veículos.

Finalmente, o descarte de materiais não recicláveis ou inservíveis provoca impactos socioambientais específicos. No caso dos pneus, por exemplo, seu caráter nãobiodegradável e volume colocam problemas de transporte e armazenamento, não sendo incomum o tratamento inadequado via queima, liberando substâncias tóxicas, ou deposição em rios $^{14}$ (GOLDENSTEIN, ALVES e BARRIOS, 2007, p. 123).

\section{O Segmento Fluminense da RGP Automotiva}

Essa seção discute as estratégias corporativas apresentadas pelas montadoras do segmento fluminense da RGPA, enfocando especialmente as dimensões do investimento, do mercado e das relações de trabalho a partir da tipologia da estratégia corporativa apresentada na seção 2 .

O estado do Rio de Janeiro tem sido objeto da expansão recente da indústria automotiva desde meados dos anos 1990. Considerando apenas as firmas líderes, o parque estadual conta com uma unidade produtora de caminhões e chassis de ônibus da MAN Latin America Indústria e Comércio de Veículos Ltda. (MAN Latin America), instalada em 1996 em Resende; duas unidades da Peugeot Citroën do Brasil Automóveis Ltda. (Peugeot Citroën) para a produção de automóveis, veículos comerciais leves e motores, 
estabelecidas em Porto Real em 2001; uma fábrica de linha amarela e veículos industriais da Hyundai Heavy Industries Brasil Indústria e Comércio de Equipamentos de Construção S.A. (HHIB), operando em Itatiaia a partir de 2013; uma unidade da Nissan do Brasil Automóveis Ltda. (Nissan), produzindo automóveis e motores em Resende desde 2014; além de uma unidade de montagem de automóveis da Jaguar e Land Rover Brasil Indústria e Comércio de Veículos Ltda. (Jaguar Land Rover), inaugurada em Itatiaia em 2016 (cf. Mapa 2).

Mapa 2. Unidades Fabris da Rede Global de Produção Automotiva, Rio de Janeiro (2019)
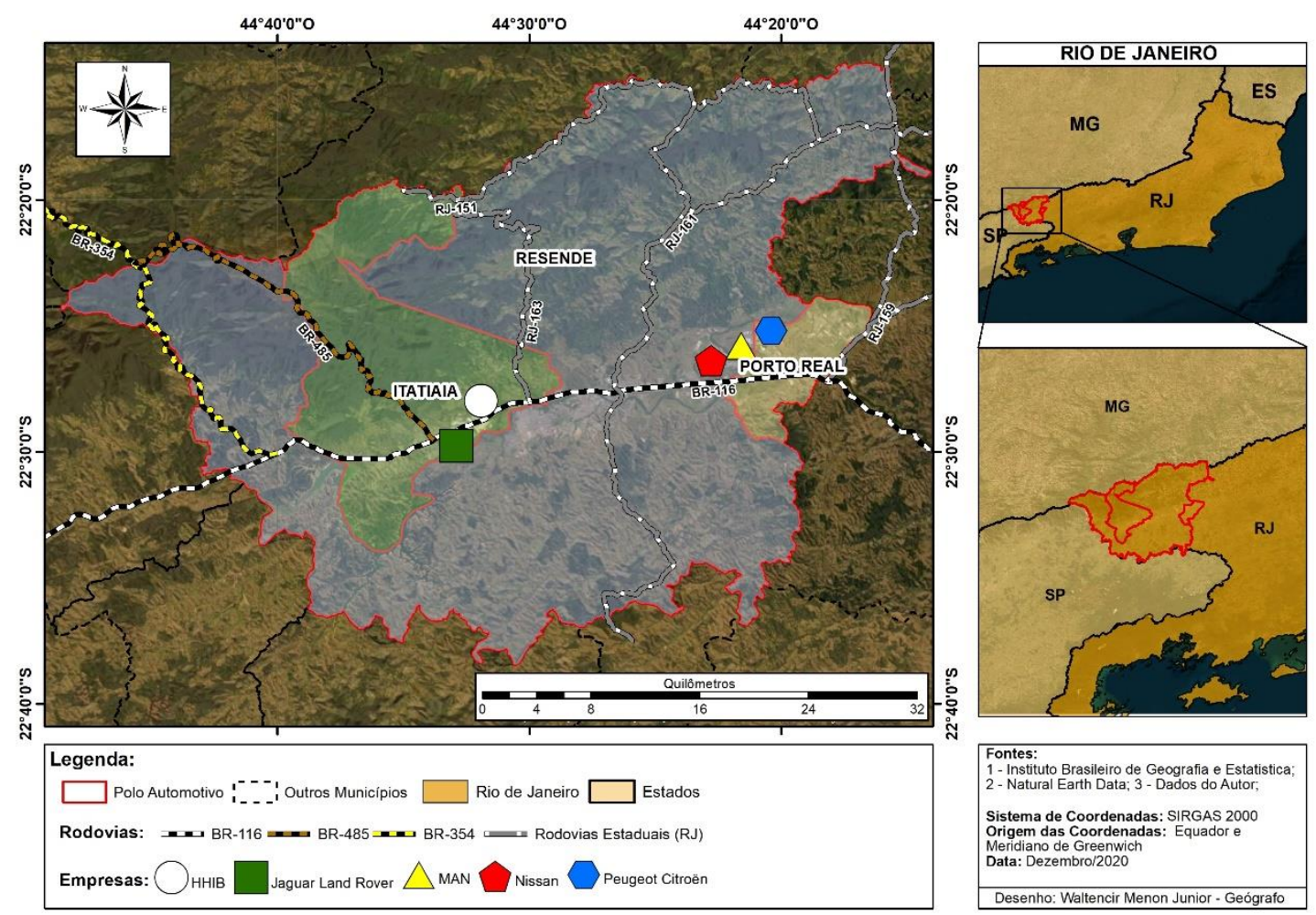

Fonte: o autor, a partir de ANFAVEA (2020).

Apesar desse movimento, o Rio de Janeiro perdeu participação percentual na produção nacional, saindo da $5^{\mathrm{a}}(7,7 \%)$ para a $7^{\mathrm{a}}(6,7 \%)$ posição entre 2018 e 2019 (ANFAVEA, 2020, p. 52). Assim, em 2019 foram produzidos 197,7 mil veículos no estado (ANFAVEA, 2020, p. 52). Não obstante, o parque automotivo estadual é um dos mais diversificados do Brasil, o que tende a impactar, de modo importante, nos padrões relacionais da RGPA, em particular no que respeita às relações de poder (HENDERSON et al., 2011) e à governança (GEREFFI, HUMPHREY e STURGEON, 2005) de rede.

É possível analisar essa diversidade no que diz respeito a 3 dimensões-chave. Em primeiro lugar, as firmas líderes apresentam diferentes origens institucionais, remetendo à história e às condições culturais e políticas, isto é, aos padrões de enraizamento social (HESS, 2004a) nos quais a ação organizacional é produzida. Desse modo, a ação organizacional das CTNs alemã MAN Latin America, japonesa Nissan, sul-coreana HHIB, indo-britânica Jaguar Land Rover e francesa Peugeot Citroën revela dinâmicas institucionais mais abrangentes, sendo particularmente importantes as economias políticas nacionais das quais se originam (HALL e SOSKICE, 2001). 
Por sua vez, as CTNs automotivas instaladas no Rio de Janeiro divergem quanto aos sistemas de produção que operam, partindo do consórcio modular na MAN Latin America (ABREU, BEYNON e RAMALHO, 2000), chegando ao modelo de condomínio industrial na Nissan e Peugeot Citroën (SABBADINI e VILLAVICENCIO, 2007) e ao completely knocked down (CKD) na Jaguar Land Rover (SANTOS, 2019). Os diferentes sistemas de produção expressam EIs (CHEN e CHEN, 2010) específicas de firmas líderes: de um lado montadoras com market share consolidado, que privilegiam a governança (GEREFFI, HUMPHREY e STURGEON, 2005) de redes de fornecimento em multi-camadas ${ }^{15}$ e um padrão de follow sourcing (STURM, 2017); e, de outro, uma montadora ingressante, cuja unidade não possui seções de fabricação de carroceria (body shop) ou mesmo de pintura (paint shop) (SANTOS, 2019, p. 10).

Finalmente, os diversos mercados atendidos e bens/serviços ofertados pelas firmas líderes devem ser segmentados em dois grupos. No primeiro, os bens de capital produzidos pela MAN Latin America (caminhões e chassis de ônibus) e pela HHIB (máquinas pesadas) estão associados a decisões de compra tipicamente corporativas e a dinâmicas de baixa ciclicidade, em algum grau, impulsionadas pelo comércio exterior; enquanto no segundo grupo, os diferentes tipos de bens de consumo ofertados pela Nissan e Peugeot Citroën (automóveis e comerciais leves, populares e médios) e pela Jaguar Land Rover (automóveis premium) são amplamente dependentes de EMs (ZOTT e AMIT, 2008), do consumo familiar e individual e de dinâmicas macroeconômicas internas. Essa segmentação apresenta repercussões importantes para a flutuação do emprego automotivo no Rio de Janeiro.

Ao longo dos últimos 10 anos (2010-2019), o emprego no nó produtivo ${ }^{16}$ do segmento estadual da RGPA flutuou consideravelmente (cf. Gráfico 1). Enquanto o estoque de empregos ${ }^{17}$ nesse segmento da rede era de 14.882 em 2019, uma redução de $3,0 \%$ em relação ao início do período, especificamente o Polo Automotivo ${ }^{18}$ contribuía $^{2}$ com 9.672 postos, respondendo por $65,0 \%$ do total estadual, uma ampliação de $15,6 \% \mathrm{em}$ relação a 2010 (MTE, 2020).

Considerando especialmente o Polo Automotivo ${ }^{19}$ e os principais empregadores nesse segmento da rede, é digna de nota a evolução progressiva do emprego automotivo em Itatiaia, onde estão localizadas a Jaguar Land Rover e a HHIB, além da fábrica de pneus da Sociedade Michelin Brasil Ltda. (Michelin). O volume de empregos no município mais que duplicou (112,5\%) entre 2010 e 2019, com 1.944 postos. Por sua vez, a inflexão negativa quase contínua nos empregos automotivos em Porto Real, que chegaram a 3.138 postos, - 45,3\% em relação ao início do período, ilustra a dependência do município dos resultados da Peugeot Citroën e das dinâmicas do subsetor de automóveis populares. Finalmente, a expressiva recuperação do emprego automotivo em Resende a partir de 2017 se vincula à notável expansão da Nissan, assim como à melhoria dos níveis de produção da MAN Latin America (cf. Gráfico 2). Desse modo, Resende gerou 4.590 postos em 2019, 167,5\% a mais que 2010 (MTE, 2020).

Os efeitos socioeconômicos relacionados ao Polo Automotivo do sul do estado do Rio de Janeiro têm sido discutidos quanto às dimensões do emprego/renda e das condições/relações de trabalho (ABREU, BEYNON e RAMALHO, 2000; DULCI, 2009; MONTEIRO e VIANA, 2018; RAMALHO e SANTANA, 2006a). Tais estudos ${ }^{20}$ acentuam o papel indutor do setor sobre a economia regional, com ênfase especial sobre a formação de um mercado de trabalho automotivo, a elevação das qualificações profissionais e o estabelecimento de um novo perfil de trabalhador industrial na região, caracterizado por salários mais elevados e melhores condições e relações de trabalho. 


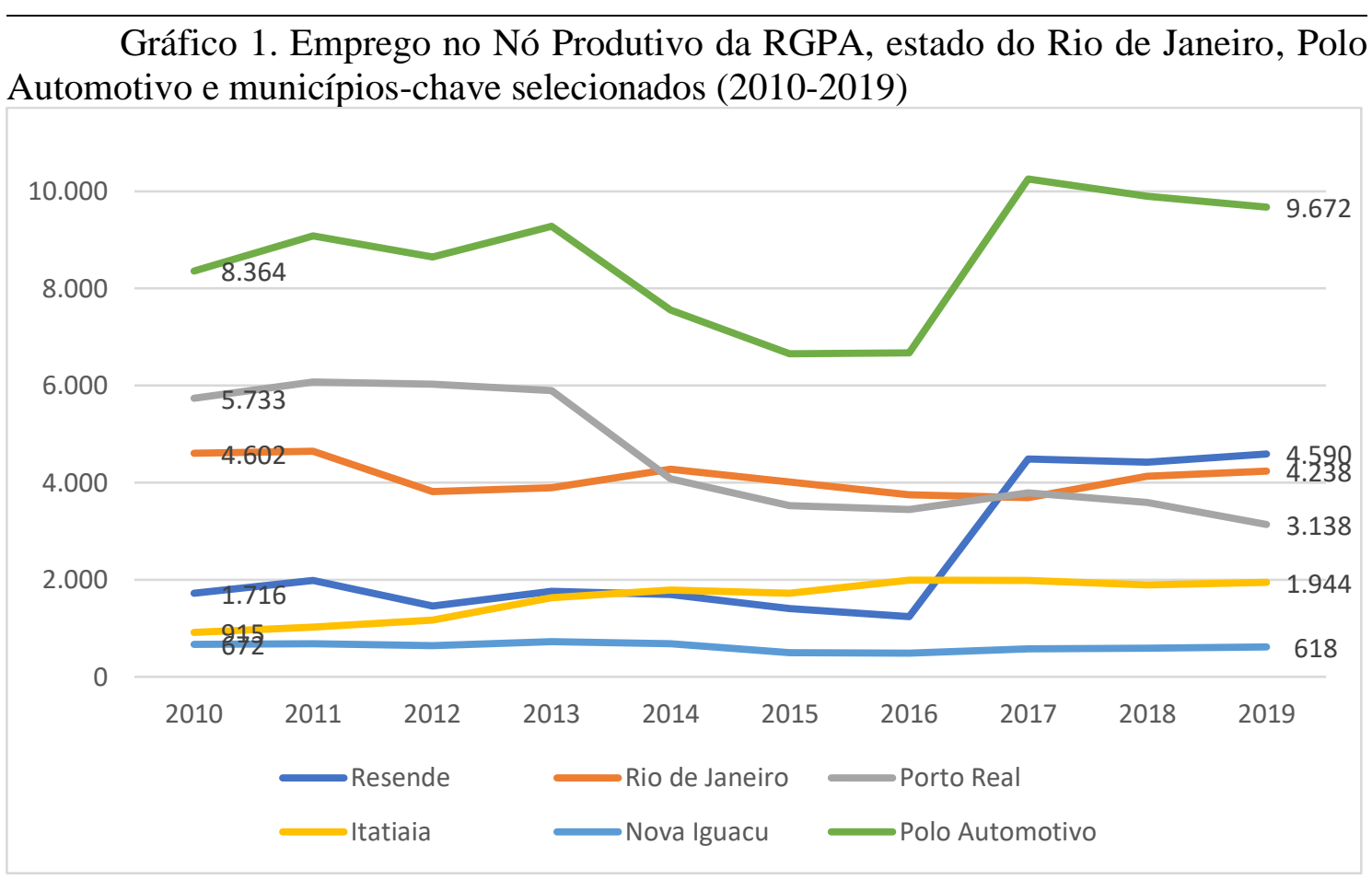

Fonte: o autor, a partir de MTE (2020).

Em anos recentes, entretanto, a situação recessiva do setor tem impactado fortemente os trabalhadores e sua organização representativa no Polo, o Sindicato dos Metalúrgicos do Sul Fluminense (SMSF), predominando padrões de ação coletiva concertada, e não confrontacional, como demonstram os exemplos da MAN Latin America e da Nissan nos últimos 5 anos (HAMDAN, 2020).

Faz-se necessário, portanto, analisar as firmas e unidades instaladas no Sul Fluminense, particularmente no que se refere a seus modelos de produção e relações de trabalho.

\subsection{MAN Latin America}

A montadora que acabaria dando origem ao Polo foi a MAN Latin America, CTN alemã que integra o grupo Volkswagen. A unidade se instalou em Resende em 1995, sendo a primeira montadora em operação no estado desde o encerramento da Fábrica Nacional de Motores (FNM), em 1985 (RAMALHO, 1989). A fábrica produz caminhões e chassis de ônibus, se destacando pela organização inovadora do processo de produção sob a forma de consórcio modular (ABREU, BEYNON e RAMALHO, 2000), assim como por ERT (MILLER, 1987) menos conflituosa, remetendo ao enraizamento social (HESS, 2004a) da CTN e a seus mecanismos específicos, a exemplo da comissão de fábrica (FRANCISCO, 2005).

Segundo a Conferência das Nações Unidas sobre Comércio e Desenvolvimento (UNCTAD), o grupo VW era a $7^{\text {a }}$ corporação automotiva mais transnacionalizada do mundo - sendo a $54^{\mathrm{a}}$ entre as CTNs não financeiras (UNCTAD, 2020). Dessa forma, $44,4 \%$ de seus ativos totais (US\$ 548,3 bilhões), 80,6\% das vendas (US\$ 282,8 bilhões) e $55,7 \%$ de seus empregados no mundo (671,0 mil) estão localizados fora de sua sede (cf. Tabela 1) (UNCTAD, 2020).

$\mathrm{Na}$ unidade de Resende, os caminhões respondiam por cerca de $88,4 \%$ da produção em $2016^{21}$ (ANFAVEA, 2020, p. 90). Em 2019, 26,7 mil caminhões e 5,5 mil 
chassis de ônibus (totalizando 32,2 mil unidades) foram licenciados (ANFAVEA, 2020, p. 90), o que indica a recuperação tímida dos níveis de produção da unidade (cf. Gráfico 2) que, em 2011 (cf. Gráfico 2), chegou a fabricar 83,1 mil unidades.

A queda drástica, iniciada em 2013, afetou de maneira importante os trabalhadores da planta. A unidade, que chegou a contar com cerca de 6 mil trabalhadores em 2011 (RIATO, 2016), operando em 3 turnos de produção, operaria com cerca da metade em 2017 (VOLKSWAGEN, 2017). Não obstante, o processo de redução da força de trabalho da montadora entre 2015 e 2017 envolveu negociação com os trabalhadores e o uso reiterado do dispositivo do Programa de Proteção ao Emprego (PPE) (WALMRATH, 2018), sugerindo a importância do enraizamento social (HESS, 2004a) na compreensão de sua ação organizacional.

Gráfico 2. Evolução da Produção de Veículos no Polo Automotivo do Rio de Janeiro (2010-2019)

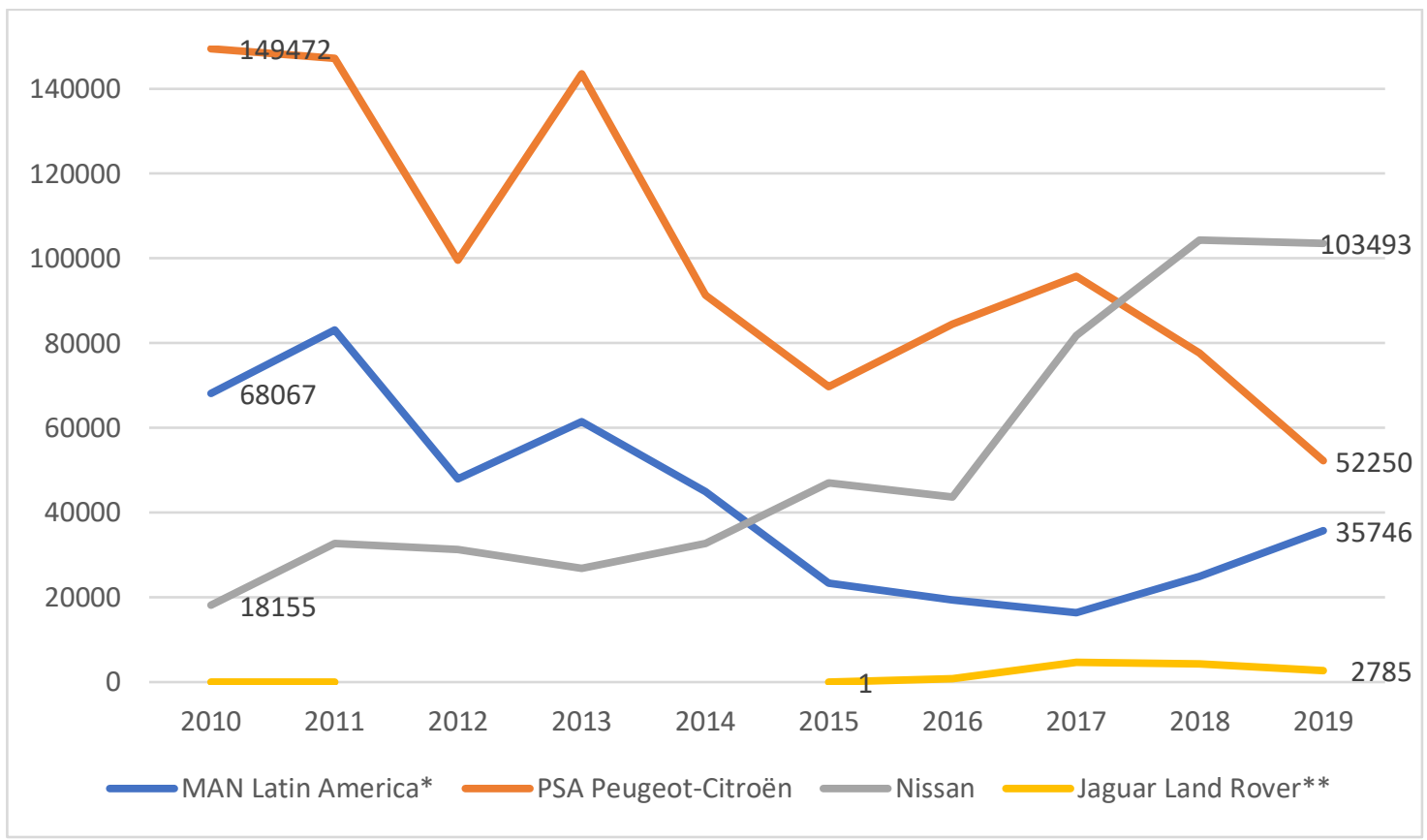

Fonte: o autor, a partir de ANFAVEA (2020).

* Os dados de produção da MAN Latin America estão disponíveis até 2016. Os dados de 2017 a 2019 se referem ao licenciamento de veículos nacionais.

** Os dados da Jaguar Land Rover ao longo de toda a série se referem ao licenciamento de veículos nacionais.

\subsection{Peugeot Citroën}

Em 2001, a CTN francesa Peugeot Citroën instalou sua primeira unidade brasileira em Porto Real (LIMA, 2005), sob um formato de produção enxuto e sob a forma de condomínio industrial (RAMALHO e SANTANA, 2006a).

O grupo PSA era a $10^{a}$ corporação automotiva mundial mais transnacionalizada do mundo, figurando na posição $66^{\mathrm{a}}$ entre as CTNs não financeiras (UNCTAD, 2020). Essa posição era sustentada pela localização no exterior de $61,1 \%$ de seus ativos (US\$ 
78,4 bilhões), $77.2 \%$ das vendas (US\$ 83,6 bilhões) e $26,9 \%$ de seus empregados $(208,8$ mil) (UNCTAD, 2020).

A fábrica de Porto Real produziu 52,3 mil automóveis em 2019, tendo encerrado a fabricação de comerciais leves já em 2017 (ANFAVEA, 2020, p. 98). Em relação a 2010, a produção total encolheu em cerca de 1/3 (ANFAVEA, 2020, p. 98), quando a planta produziu 149,5 unidades. A recuperação restrita que se observou em 2016 e 2017 se reverteu rapidamente já em 2018 (cf. Gráfico 2).

A queda na produção também afetou o emprego na planta, de maneira que já no início de 2014, a montadora reduzia as operações para dois turnos, implementava o layoff e o Programa de Demissão Voluntária, demitindo cerca de 700 trabalhadores. Comparativamente, o uso predominante desses dispositivos reforça achados empíricos acerca de um padrão conflituoso de relações de trabalho, caracterizado parcialmente por "práticas autoritárias" e pressão sobre os trabalhadores (RAMALHO e SANTANA, 2006a, p. 127). Em 2018, a montadora já operava com cerca de 2 mil trabalhadores (A VOZ DA CIDADE, 2018b).

\subsection{Nissan}

Em 2014, a Nissan inaugurou uma nova unidade em Resende. A empresa faz parte da Aliança Renault-Nissan desde 1999, um acordo de cruzamento acionário entre os grupos francês Renault SA e japonês Nissan Motor Co. Em 2017, a Mitsubishi tornou-se parceira igualitária, alterando sua denominação para Aliança Renault-Nissan-Mitsubishi (RENAULT-NISSAN-MITSUBISHI, 2017).

Segundo a UNCTAD, Nissan Motor Co. e Renault estavam entre as 10 corporações automotivas mais transnacionalizadas do mundo em 2019 (UNCTAD, 2020). A CTN japonesa era a $3^{\mathrm{a}}$ colocada ( $36^{\mathrm{a}}$ entre as não financeiras), enquanto sua parceira francesa era a $6^{\mathrm{a}}\left(51^{\mathrm{a}}\right.$ entre as não financeiras). No que respeita aos ativos no exterior a Nissan Motor Co. $(71,5 \%)$ está à frente da Renault $(45,1 \%)$, assim como nas vendas, com as receitas de venda da montadora japonesa $(83,5 \%)$ menos dependentes do mercado doméstico da matriz, ainda que a CTN francesa $(75,1 \%)$ mostre elevada internacionalização. No entanto, a proporção de empregados no exterior é muito maior na Renault (73,3\%) do que na Nissan Motor Co. (57,2\%), que respondem por 179,6 mil e 138,9 mil trabalhadores no mundo, respectivamente (UNCTAD, 2020).

A unidade de Resende é um complexo para a produção de veículos da marca Nissan e motores, organizada como um condomínio industrial abrangendo apenas fornecedoras de primeira camada de origem japonesa, i.e. Tachi-S, Yorozu, Kinugawa, Calsonic Kansei, Sanoh e Mitsui Steel (WALMRATH, 2021, p. 177), diretamente implicadas na montagem. Em conjunto com a adoção de dinâmicas organizacionais e de mecanismos de qualificação profissional, parcialmente realizada no Japão (WALMRATH, 2021, p. 178-179), o dado sugere que o nível de enraizamento social (HESS, 2004a) da Nissan é notadamente elevado.

Em 2019, a planta produziu 103,5 mil automóveis (ANFAVEA, 2020, p. 95), sendo a produção de comerciais leves encerrada já em 2016. Não obstante, a produção vem se ampliando progressivamente desde 2014, tendo mais do que triplicado desde então (cf. Gráfico 2).

Operando inicialmente com cerca de 1,8 mil funcionários (NUNES, 2014), a crise do setor se expressou no atraso para o estabelecimento do $2^{\circ}$ turno (A VOZ DA CIDADE, 2018b), assim como em uma operação de layoff, que reduziu sua força de trabalho a 1,4 mil funcionários $(\mathrm{G} 1,2014)$. No entanto, a expansão da produção em anos recentes vem 
contrabalançando parcialmente as perdas de postos nas outras montadoras. Em 2018, a unidade operava em 2 turnos com cerca de 2,4 mil trabalhadores (AUTOMOTIVE BUSINESS, 2018).

\subsection{Jaguar Land Rover}

A unidade da indo-britânica Jaguar Land Rover, subsidiária do grupo Tata Motors Ltd., foi inaugurada em Itatiaia em 2016, sendo a primeira fora do Reino Unido. A montadora opera a partir do sistema completely knocked down (CKD), no qual a matriz fornece à subsidiária kits das partes não montadas com vistas ao ingresso e ampliação de market share no novo mercado ${ }^{22}$.

Assim, a montagem dos kits dos modelos Range Rover Evoque e Discovery Sport em Itatiaia se expandiu rapidamente desde sua introdução em 2016 (753 unidades), tendo sido montados 4.672 veículos em 2017 (ANFAVEA, 2020). No entanto, as condições do segmento de automóveis premium se deterioram progressivamente, de modo que o resultado da montadora em 2019 se contraiu, com a montagem de 2.785 unidades (cf. Gráfico 2), 59,6\% da produção de 2017.

O modelo produtivo CKD é, em geral, pouco intensivo em mão de obra. Dessa forma, em sua implantação, a Jaguar Land Rover contava com 400 funcionários em 2016 (MORETZSOHN, 2016). Enquanto no início de 2017 a unidade já havia reduzido seu contingente para 320 trabalhadores (ÉPOCA NEGÓCIOS, 2017), dados mais recentes dão conta que a montadora operava com "200 trabalhadores diretos, além de contar com um número entre 150 e 200 trabalhadores terceirizados” em turno único (SANTOS, 2019, p. $7)$.

Desse modo, as EI (CHEN e CHEN, 2010) e ERT (MILLER, 1987) da Jaguar Land Rover se combinam em um padrão de gestão estratégica (HEIDENREICH, 2012) das condições de enraizamento territorial (HENDERSON et al., 2011, p. 160) da montadora indo-britânica no Sul Fluminense.

Contudo, "a discrepância entre o cenário projetado e o mercado para veículos 'premium' no Brasil teria criado oportunidades" (SANTOS, 2019, p. 7) para os agentes locais - trabalhadores e gestores, especificamente no que se refere ao reforço dos padrões de qualidade da marca. Dessa forma, em face da redução do nível de utilização da capacidade instalada da planta, esses agentes estariam redefinindo as atividades da unidade, em favor da "ampliação da oferta de serviços em seu portfólio" (SANTOS, 2019, p. 11), buscando reduzir a vulnerabilidade de rede da unidade e reconfigurar seu papel na RGP da Jaguar Land Rover.

\subsection{HHIB}

A operação brasileira do grupo sul-coreano Hyundai Heavy Industries, atuante nos setores de construção naval, engenharia industrial e máquinas de construção (LAGUNA e FERNANDES, 2013), constitui a primeira unidade da divisão de equipamentos de construção do grupo fora da Ásia (HHIB, 2020).

Instalada em Itatiaia (RJ) desde 2013, a HHIB se dedica à chamada linha amarela (máquinas pesadas), produzindo escavadeiras, pás-carregadeiras, retroescavadeiras, assim como veículos industriais, como empilhadeiras e rolos compactadores (HHIB, 2020).

Com um investimento na unidade de US\$ 180 milhões, o modelo de ingresso da HHIB no mercado brasileiro de bens de capital foi a joint venture, de modo que a unidade é operada pela BMC Hyundai S.A. (BMCH) (ALONSO, 2013), de propriedade de 
brasileira BMC Máquinas e Equipamentos Ltda. (BMC), que detém $25 \%$ do empreendimento, e da HHIB (75\%) (LAGUNA, 2011). A forma de ingresso é também indicativa da gestão estratégica das condições de enraizamento (HEIDENREICH, 2012), priorizando o conhecimento e a ampliação progressivos de market share.

Assim, a capacidade instalada da unidade é de 4 mil equipamentos de linha amarela ao ano, importando "os outros produtos vendidos" (ALONSO, 2013). Embora os dados sobre produção não estejam disponíveis, a HHIB celebrava a fabricação de 2.000 máquinas no início de 2018 (HHIB, 2018), sugerindo que a fábrica opera com níveis de utilização reduzidos.

O anúncio da decisão de investimento da HHIB deu origem a expectativas de geração de até 1.500 postos de trabalho, diretos e indiretos (SMSF, 2012, p. 1). Dados mais conservadores indicavam que a unidade mobilizaria 800 trabalhadores em 2013 (SMC, 2013). Os dados da Relação Anual de Informações Sociais (RAIS) apontam, no entanto, que a unidade não ultrapassou 428 empregos em seu $1^{\circ}$ ano de operação, que se retraíram para 292 trabalhadores em 2019, uma queda de quase 2/3 (MTE, 2020).

\section{Conclusão}

O artigo apresentou uma análise do segmento brasileiro da RGPA, apresentando a estrutura dos nós ou agrupamentos de atividades econômicas que a conformam e focalizando um segmento de rede correspondente às firmas líderes do Polo Automotivo do Rio de Janeiro. O nível de abstração da análise da estrutura da RGPA correspondeu ao objetivo de mapeamento da contribuição das relações entre agentes na rede, que produz impactos sistêmicos sobre a capacidade de ação, individual e coletiva - em especial, organizacional, em escala nacional. Por sua vez, o enfoque em agentes-chave econômicos à escala do Polo Automotivo permitiu, ainda, observar padrões de diversidade institucional, produtiva e de mercado/setor, que indicam enorme potencial de generalização.

Nesses termos, o artigo apresentou uma contribuição inovadora, delimitando metodologicamente as atividades econômicas e, consequentemente, os postos de trabalho a elas associadas, que compreendem a RGPA no Brasil, por meio da reunião de 17 subclasses da CNAE, cf. nota 16. A referida tipificação transcendeu a dimensão metafórica da noção de rede de produção e permitiu a representação de seu nó produtivo no Rio de Janeiro - ainda que seja necessário problematiza-la e ampliá-la de modo a permitir estudos empíricos sobre as atividades econômicas e relações de trabalho em toda a rede.

Os resultados explicitaram ainda a natureza diversificada do nó produtivo do Polo Automotivo do Sul Fluminense, assim como sua centralidade na conformação do setor no estado do Rio de Janeiro, a partir da análise das dimensões do investimento, do mercado e das relações de trabalho das 5 firmas líderes, operacionalizada por meio da introdução de uma tipologia da estratégia corporativa.

Dessa forma, os processos de valor e o poder corporativo das firmas líderes foram mediados por condições - e formas de sua gestão - de enraizamento distintas, particularmente em suas modalidades social e territorial. Em sentido prático, a combinação desses três elementos em estratégias corporativas singulares responde, em grande medida, pela diversidade dos efeitos sobre os trabalhadores - e para a qualidade das relações de trabalho -, assim como para a desigualdade dos impactos sobre a renda na região.

As transformações recentes nos segmentos fluminense e brasileiro da RGPA convergem ainda com resultados internacionais, que indicam que as montadoras vêm 
conseguindo reestruturar suas redes de produção em benefício próprio, i. transferindo atividades (e riscos associados) à criação de valor, ii. ampliando valor por meio da concentração em atividades a montante e a jusante da manufatura, e iii. capturando valor através da recomposição da estrutura de custos de produção e circulação ao longo de toda a rede. Nesses termos, a despeito da complexidade dos processos de efetivação de suas estratégias corporativas, nas escalas analíticas nacional e regional, dinâmicas de poder vêm subordinando os padrões de enraizamento, em especial territoriais.

Os resultados da investigação, apesar de promissores, demandam complementação e especificação. No primeiro caso, é necessário investigar as relações entre os segmentos da RGPA, por exemplo, entre a produção de componentes e a distribuição (cf. Figura 1), amplamente ignoradas, de modo a obter maior clareza acerca das formas gerais de exercício de poder via transferência de custos e riscos e, consequentemente, de captura de valor. Por sua vez, as conexões analisadas, em grande medida, abstratamente, exigem pesquisa empírica aprofundada por meio de estudos de caso e trabalhos comparativos, enfocando firmas líderes e, principalmente, fornecedoraschave, cuja ação organizacional é virtualmente ignorada na literatura especializada sobre o setor no Brasil. Além disso, o papel dos agentes não econômicos e sua capacidade de exercício de poder na conformação da RGPA não puderam ser explorados no artigo, embora venham sendo objeto de análise em outros trabalhos (e.g. SANTOS, 2007), demandando incorporação em investigações futuras.

Finalmente, é provável que a expansão de trabalhos acadêmicos inspirados na análise de sistemas transnacionais de produção (STPs) não dê conta da velocidade das transformações que vêm caracterizando o setor automotivo, assim como as dinâmicas de seus principais agentes. No entanto, a perspectiva aqui apresentada parece ser ampla e, especialmente, plástica, permitindo integrar essas mudanças e perseguir os segmentos responsáveis pelo movimento da RGPA, como o artigo se propôs a fazer.

\footnotetext{
Notas

Esse artigo se apoia em pesquisa financiada pelo edital Jovem Cientista do Nosso Estado (JCNE), da Fundação de Amparo à Pesquisa do Estado do Rio de Janeiro (FAPERJ). Uma versão prévia do trabalho foi apresentada, em colaboração com José Ricardo Ramalho (UFRJ), no Seminário PGPSE/CAPES "Configurações do Desenvolvimento, Trabalho e Ação Coletiva", se beneficiando de críticas e sugestões da/os participantes. Uma versão ligeiramente modificada será publicada no livro Cadeias de Valor e Desenvolvimento no Sul Fluminense, organizado por Raphael Lima, Cristiano Monteiro e Alessandro Leme (no prelo).

${ }^{2}$ A noção de nó (node, no original) é insuficientemente teorizada na abordagem das RGPs, sendo associada recorrentemente a agentes, agrupamentos de atividades econômicas e/ou territórios (COE e YEUNG, 2015; HENDERSON et al., 2011). Nesse artigo, a noção é utilizada exclusivamente como sinônimo de grupos de atividades ou etapas econômicas (e.g. fornecimento, engenharia \& design, produção de componentes, etc.). ${ }^{3}$ As passagens traduzidas são de responsabilidade do autor.

${ }^{4}$ Para uma definição operacional ligeiramente diversa e empiricamente aplicada à indústria extrativa mineral, ver SANTOS e MILANEZ (2017).

${ }^{5}$ A MAN Latin America exemplifica essa tendência, já que "somente pequenas alterações de estilo são realizadas pela engenharia na fábrica de Resende e as alterações mais significativas, que definem o produto, são centralizadas pela matriz alemã” (MAGGI, 2018, p. 84).

${ }^{6}$ Em 1990, a produção de autoveículos era quase totalmente realizada nos estados de São Paulo $(74,8 \%)$ e Minas Gerais (24,5\%), segundo dados da ANFAVEA (2018, p. 58).

${ }^{7}$ A modularização (ABREU, BEYNON e RAMALHO, 2000) como expressão-chave da “desverticalização das montadoras" foi acompanhada, assim, pela "integração vertical dos fornecedores de $1^{\circ}$ nível" (TORRES e CARIO, 2013, p. 79), sendo tais movimentos indissociáveis.
} 
${ }^{8}$ No Polo Automotivo do Rio de Janeiro, cerca de 300 "motoristas autônomos proprietários de caminhões cegonhas" (A VOZ DA CIDADE, 2018a) estão reunidos sob o Sindicato das Empresas e Autônomos de Transporte Rodoviário de Veículos do Estado do Rio de Janeiro (SINTRAV-RJ), tendo questionado recentemente a decisão da Gefco Logística do Brasil Ltda. (Gefco), fornecedora de $1^{\mathrm{a}}$ camada da Peugeot Citroën, de substituí-los pela empresa BSM (A VOZ DA CIDADE, 2018a).

${ }^{9}$ As vendas no atacado (grandes volumes) tendem a ser realizadas, no entanto, através de negociações diretas com as montadoras.

${ }^{10}$ Proporção entre vendas de automóveis usados e emplacamento de novas unidades.

${ }^{11}$ Entretanto, "o percentual de veículos recuperados em relação aos quantitativos de veículos roubados ou furtados tem flutuado de forma estável na faixa entre $43 \%$ e $50 \%$ nos últimos onze anos" (ISP, 2016, p. 6).

${ }^{12}$ Em menor medida, o mercado ilegal compreende, ainda, carros 'esquentados' (LEITÃO, 2013), que recebem documentação adulterada e retornam aos canais de revenda, em geral, com preços abaixo dos do mercado formal.

${ }^{13} \mathrm{O}$ aço é o principal componente na composição de um automóvel, atingindo entre 700 e $800 \mathrm{Kg}$ por unidade produzida (DICKEN, 2007, p. 485).

${ }^{14}$ No Brasil, a Resolução CONAMA n. 258/99 estabeleceu metas de coleta e destinação adequada de pneus, obrigando as fabricantes a recolher $80 \%$ dos pneus vendidos no mercado nacional a partir de 2005 , o que não vem ocorrendo a contento (GOLDENSTEIN, ALVES e BARRIOS, 2007, p. 123).

${ }^{15}$ A estrutura é pouco conducente à incorporação de firmas domésticas, tipicamente menos aptas à realização de atividades intensivas em habilidades, valor adicionado e tecnologia.

${ }^{16} \mathrm{O}$ artigo operacionaliza essa noção a partir da reunião de 17 subclasses da Classificação Nacional de Atividades Econômicas (CNAE), em sua versão 2.0, a saber: Fabricação de Automóveis, Camionetas e Utilitários; Fabricação de Bancos e Estofados para Veículos Automotores; Fabricação de Baterias e Acumuladores para Veículos Automotores; Fabricação de Cabines, Carrocerias e Reboques para Outros Veículos Automotores, Exceto Caminhões e Ônibus; Fabricação de Caminhões e Ônibus; Fabricação de Chassis com Motor para Automóveis, Camionetas e Utilitários; Fabricação de Máquinas e Equipamentos para Terraplenagem, Pavimentação e Construção, Peças e Acessórios, Exceto Tratores; Fabricação de Material Elétrico e Eletrônico para Veículos Automotores, Exceto Baterias; Fabricação de Motores para Automóveis, Camionetas e Utilitários; Fabricação de Motores para Caminhões e Ônibus; Fabricação de Outras Peças e Acessórios para Veículos Automotores não Especificadas Anteriormente; Fabricação de Peças e Acessórios para o Sistema de Direção e Suspensão de Veículos Automotores; Fabricação de Peças e Acessórios para o Sistema de Freios de Veículos Automotores; Fabricação de Peças e Acessórios para o Sistema Motor de Veículos Automotores; Fabricação de Peças e Acessórios para os Sistemas de Marcha e Transmissão de Veículos Automotores; Fabricação de Pneumáticos e de Câmaras-de-Ar; e Fabricação de Veículos Militares de Combate. Para uma definição operacional mais restrita, ver DULCI (no prelo).

${ }^{17}$ A relevância dos municípios de Nova Iguaçu e, principalmente, do Rio de Janeiro para a geração de empregos automotivos demonstra que o Polo Automotivo se distingue do nó fluminense da RGPA. Em Nova Iguaçu, a Rassini-NHK Autopeças Ltda. e a subclasse de Fabricação de peças e acessórios para o sistema de direção e suspensão de veículos automotores respondiam por 97,2\% dos empregos em 2019; enquanto a Unidade Campo Grande da Sociedade Michelin de Participações Industriais e Comércio Ltda. e a subclasse de Fabricação de pneumáticos e de câmaras-de-ar atingiam 86,1\% dos empregos automotivos gerados no município do Rio de Janeiro no mesmo ano. Comparativamente, o emprego no Polo Automotivo é mais distribuído em subclasses e estruturalmente dependente das montadoras e de suas redes de fornecimento em camadas.

${ }^{18}$ Inclui os municípios de Itatiaia, Porto Real, e Resende, onde se concentram as firmas líderes do nó fluminense da RGPA (cf. Mapa 2).

${ }^{19} \mathrm{O}$ município de Quatis não apresentou vínculos ao longo de todo o período (MTE, 2020).

${ }^{20}$ Parcela expressiva dessa literatura discute também a dimensão sociopolítica e institucional das mudanças provocadas pelo estabelecimento do Polo, vinculadas a políticas públicas, aos regimes de cooperação público-privado e ao processo de desenvolvimento da região (LIMA e PAIVA, 2020; RAMALHO, 2005; 2015; RAMALHO e SANTANA, 2006b; SANTOS, 2007).

${ }^{21}$ Os dados de produção a partir de 2017 não estão disponíveis.

${ }^{22}$ No entanto, esse padrão de implante tende a restringir a transferência de tecnologia e a escala de produção, assim como o impacto de políticas de conteúdo local e, não menos importante, as possibilidades de industrial upgrading (FREITAS, MENEGON e DA COSTA, 2017, p. 1458). 


\section{Referências}

A VOZ DA CIDADE. Cegonheiros autônomos fazem manifestação contra a contratação de empresa para o transporte de carros da Peugeot. A Voz da Cidade, 19/1/2018. Disponível em: https://avozdacidade.com/cegonheiros-autonomos-fazem-manifestacao-contra-a-contratacao-de-empresapara-o-transporte-de-carros-da-peugeot/. Acesso em: 27/7/2018.

A VOZ DA CIDADE. Grupo PSA anuncia produção em Porto Real de C4 Cactus. A Voz da Cidade,, 27/3/2018. Disponível em: https://avozdacidade.com/grupo-psa-anuncia-producao-de-novo-carro-emporto-real/. Acesso em: 30/7/2018.

ABDALA, V. Polícia faz operação para prender acusados de fraudes com veículos. Agência Brasil, 26/4/2017. Disponível em: http://agenciabrasil.ebc.com.br/geral/noticia/2017-04/policia-faz-operacaopara-prender-acusados-de-fraudes-com-veiculos. Acesso em: 27/7/2018.

ABREU, A. R. d. P.; BEYNON, H.; RAMALHO, J. R. 'The Dream Factory': VW's Modular Production System in Resende, Brazil. Work, Employment and Society, 14, n. 2, p. 265-282, 2000.

ALONSO, O. BMC-Hyundai estima receita de R \$ 900 milhões, puxada por MDA. Valor Econômico, 14 jul. 2014. Disponível em: https://valor.globo.com/empresas/noticia/2014/07/14/bmc-hyundai-estimareceita-de-r-900-milhoes-puxada-por-mda.ghtml Acesso em: 6 dez. 2020.

ALVES, P. F. Uma analise empírica do mercado de revenda de carros usando raspagem de dados da internet. 2016. 161 f. (Doutorado) - Departamento de Economia, Universidade de Brasília, Brasília. Disponível em: http://repositorio.unb.br/bitstream/10482/20037/1/2016_PatrickFrancoAlves.pdf.

ANFAVEA. Anuário da Indústria Automobilística Brasileira 2018. ANFAVEA. São Paulo, p. 152. 2018.

ANFAVEA. Anuário da Indústria Automobilística Brasileira 2020. ANFAVEA. São Paulo, p. 143. 2020.

AUTOMOTIVE BUSINESS. Nissan completa 4 anos em Resende no topo da capacidade. Automotive Business, 17/4/2018. Disponível em: http://www.automotivebusiness.com.br/noticia/27316/nissancompleta-4-anos-em-resende-no-topo-da-capacidade. Acesso em: 30/7/2018.

BENDER, R.; WARD, K. Corporate Financial Strategy. 3rd ed. Oxford: Elsevier ButterworthHeinemann, 2009.

BONASSA, A. C. O problema da formação de carga e distribuição de veículos zero-quilômetro. 2018. 196 f. (Doutorado) - Escola Politécnica, Universidade de São Paulo, São Paulo.

BUELL, J. From the Model T to the Hummer: The Economics and Aesthetics of the American Automobile. In: Politics, Religion, and Culture in an Anxious Age: Springer, 2011. p. 47-75.

CARVALHO, I. Como funciona uma linha de montagem de automóveis? Revista Quatro Rodas, 1/5/2017. Disponível em: https://quatrorodas.abril.com.br/noticias/como-funciona-uma-linha-demontagem-de-automoveis/. Acesso em: 27/7/2018.

CASTELLS, M. A Sociedade em Rede. A Era da Informação: economia, sociedade e cultura. São Paulo: Paz e Terra, 1999.

CASTRO, B. H. R. d.; BARROS, D. C.; VAZ, L. F. H. Panorama da engenharia automotiva no Brasil: inovação e o apoio do BNDES. 2014.

CHEN, Y.-R.; CHEN, J.-Y. The Incentive Effect of Executive Stock Options on Corporate Investment Strategy: the evidence of strategic alliance. In: The 2010 Financial Management Association Annual Meeting, 2010, New York. Oct. 2010.

COE, N. M.; YEUNG, H. W.-C. Global production networks: Theorizing economic development in an interconnected world. Oxford University Press, 2015.

DA COSTA, R. M.; HENKIN, H. Estratégias competitivas e desempenho da indústria automobilística no Brasil. Economia e Sociedade, 25, n. 2, p. 457-487, 2016. 
DAVIS, G. F. Firms and Environments. In: SMELSER, N. J. e SWEDBERG, R. (Ed.). The Handbook of Economic Sociology. 2nd ed. Princeton; Oxford; New York: Russel Sage Foundation; Princeton University Press, 2005. p. 478-502.

DICKEN, P. 'Wheels of change': the automobile industry. In: DICKEN, P. (Ed.). Global shift: mapping the changing contours of the world economy. 7 ed. New York; London: The Guilford Press, 2007. cap. 15, p. 477-509.

DICKEN, P. Transnational Corporations: the primary 'movers and shapers' of the global economy. In: DICKEN, P. (Ed.). Global Shift: mapping the changing contours of the world economy. 6th ed. London: Sage, 2011. cap. 5, p. 109-168.

DULCI, J. A. Reestruturação produtiva e mercado de trabalho no Vale do Paraíba Fluminense: região ganhadora ou perdedora. 2009. Dissertação (Curso de Mestrado)-Escola Nacional de Ciências Estatísticas. Programa de Pós-Graduação em Estudos Populacionais e Pesquisas Sociais. Rio de Janeiro.

DULCI, J. A. Crise, Emprego e Renda na Indústria Automotiva: os casos de Sul Fluminense, Camaçari e Grande ABC Paulista em perspectiva comparada. Sociologia \& Antropologia, no prelo.

ÉPOCA NEGÓCIOS. Nova política industrial vai definir projetos da Land Rover no Brasil. Época Negócios, 3/3/2017. Disponível em: https:/epocanegocios.globo.com/Empresa/noticia/2017/03/epocanegocios-nova-politica-industrial-vai-definir-projetos-da-land-rover-no-pais.html. Acesso em: 30/7/2018.

FELTRAN, G. d. S.; HORTA, F. M. Carros, Drogas, Seguros: negócios articulados. In: LABATE, B. C. e RODRIGUES, T. (Ed.). Política de Drogas no Brasil: Conflitos e Alternativas. Campinas: Mercado de Letras, 2019. p. 169-198.

FENABRAVE. Anuário 2019. O Desempenho da Distribuição Automotiva no Brasil. FENABRAVE. São Paulo, p. 84. 2020.

FENAUTO. FENAUTO. 2018. Disponível em: http://www.fenauto.org.br/. Acesso em: 27/7/2018.

FERNANDES, M. A. B. Simulação computacional aplicada ao planejamento e projeto da área de armação de carrocerias na indústria automobilística. 2009. -, Universidade de São Paulo.

FRANCISCO, E. M. V. A Comissão Enxuta: ação política na fábrica do consórcio modular em Resende. Florianópolis: EdUSC, 2005. 352 p.

FREITAS, L. D.; MENEGON, N. L.; DA COSTA, M. A. B. Logística de uma montadora automobilística completely knocked down. Revista Produção Online, 17, n. 4, p. 1454-1479, 2017.

FRIGANT, V.; ZUMPE, M. Regionalisation or globalisation of automotive production networks? Lessons from import patterns of four European countries. Growth and Change, 48, n. 4, p. 661-681, 2017.

G1. Nissan suspende contrato de 279 funcionários em Resende, RJ. 10/9/2014. Disponível em: http://g1.globo.com/rj/sul-do-rio-costa-verde/noticia/2014/09/nissan-suspende-contrato-de-279-

funcionarios-em-resende-rj.html. Acesso em: 30/7/2018.

GEREFFI, G. The Global Economy: organization, governance, and development. In: SMELSER, N. J. e SWEDBERG, R. (Ed.). The Handbook of Economic Sociology. 2nd ed. Princeton; Oxford; New York: Russel Sage Foundation; Princeton University Press, 2005. p. 160-182.

GEREFFI, G.; HUMPHREY, J.; STURGEON, T. The governance of global value chains. Review of international political economy, 12, n. 1, p. 78-104, 2005.

GOLDENSTEIN, M.; ALVES, M. d. F.; BARRIOS, M. T. Panorama da Indústria de Pneus no Brasil: Ciclo de investimentos, novos competidores e a questão do descarte de pneus inservíveis. 2007.

GOULART, G. Roubo de carro: Rio tem quase 500 ferros-velhos clandestinos. O Globo, 19/4/2018. Disponível em: https://oglobo.globo.com/rio/roubo-de-carro-rio-tem-quase-500-ferros-velhosclandestinos-22609554. Acesso em: 27/7/2018.

GRANOVETTER, M. Economic Action and Social Structure: the problem of embeddedness. American Journal of Sociology, 91, n. 3, p. 481-510, 1985.

HALL, P. A.; SOSKICE, D. (ed.). Varieties of Capitalism: the institutional foundations of comparative advantage. Oxford: OUP, 2001. 557 p. 
HAMDAN, T. D. Variedades de Relações Industriais: capacidade de barganha dos sindicatos nas corporações da indústria automobilística. Revista do CFCH, p. 1-4, 2020.

HEIDENREICH, M. The Social Embeddedness of Multinational Companies: a literature review. SocioEconomic Review, 10, n. 3, p. 549-579, 2012.

HENDERSON, J.; DICKEN, P.; HESS, M.; COE, N. M. et al. Redes de produção globais e a análise do desenvolvimento econômico. Revista Pós Ciências Sociais, 9, n. 15, p. 143-140, 2011.

HERNÁNDEZ, M. A. Alternativas para el análisis de las multinacionales. ¿Hacia dónde va el Neoinstitucionalismo? Revista Trabajo, 8, n. 12, p. 25-58, 2014.

HEROD, A.; PICKREN, G.; RAINNIE, A.; MCGRATH CHAMP, S. Global destruction networks, labour and waste. Journal of Economic Geography, 14, n. 2, p. 421-441, 2013.

HESS, M. Global Production Networks: dealing with diversity. In: HAAK, R. e TACHIKI, D. S. (Ed.). Regional strategies in a global economy: multinational corporations in East Asia. München: IUDICIUM Verlag, 2004a. v. 38, p. 31-52.

HESS, M. 'Spatial' Relationships? Towards a reconceptualization of embeddedness. Progress in Human Geography, 28, n. 2, p. 165-186, 2004b.

HHIB. 2000 Máquinas. 1 fev. 2018. Disponível em: https://www.hhib.com.br/blog/post/16/2000-m-quinas. Acesso em: 5 dez. 2020.

HHIB. A Fábrica. 2020. Disponível em: https://www.hhib.com.br/hyundai/grupo\#. Acesso em: 6 dez.

ISP. Relatório Temático Roubo de Veículos. Instituto de Segurança Pública. Rio de Janeiro, 44 p. 2016.

KNIGHTS, D.; MORGAN, G. Corporate Strategy, Organizations, and Subjectivity: a critique. Organization Studies, 12, n. 2, p. 251-273, 1991.

LAGUNA, E. Hyundai começa obras de sua fábrica de máquinas no Rio de Janeiro. Valor Econômico, 7 out. 2011. Disponível em: https://valor.globo.com/empresas/noticia/2011/10/07/hyundai-comeca-obrasde-sua-fabrica-de-maquinas-no-rio-de-janeiro.ghtml Acesso em: 6 dez. 2020.

LAGUNA, E.; FERNANDES, A. Hyundai faz chegada meteórica ao Brasil. Valor Econômico, 3 mai. 2013. Disponível em: https://valor.globo.com/empresas/noticia/2013/05/03/hyundai-faz-chegadameteorica-ao-brasil.ghtml Acesso em: 6 dez. 2020.

LEITÃO, M. Guerra à máfia das 'robautos' no Rio. O Dia, 16/6/2013. Disponível em: https://odia.ig.com.br/_conteudo/noticia/rio-de-janeiro/2013-06-16/guerra-a-mafia-das-robautos-norio.html. Acesso em: 27/7/2018.

LIM, L. L.; ALPAN, G.; PENZ, B. Reconciling sales and operations management with distant suppliers in the automotive industry: a simulation approach. International Journal of Production Economics, 151, p. 20-36, 2014.

LIMA, R. J. d. C. Açúcar, Coca-Cola e Automóveis: ação político-empresarial na construção de um "município modelo" em Porto Real (RJ). Orientador: RAMALHO, J. R. 2005. (Mestrado) - Programa de Pós-Graduação em Sociologia e Antropologia (PPGSA), Universidade Federal do Rio de Janeiro, Rio de Janeiro.

LIMA, R. J. d. C.; PAIVA, A. D. d. O Cluster Automotivo Sul Fluminense: experiência de arranjo produtivo ou arranjo institucional? Desenvolvimento em Questão, 18, n. 50, p. 10-23, 2020.

MAGGI, D. M. Criando Valor para além da Fábrica? Um estudo sobre a estratégia de marca da MAN Latin America. 2018. 125 f. (Mestrado) - Programa de Pós-Graduação em Sociologia e Antropologia, Universidade Federal do Rio de Janeiro, Rio de Janeiro.

MILLER, P. Strategic Industrial Relations and Human Resource Management: distinction, definition and recognition. Journal of Management Studies, 24, n. 4, p. 347-361, 1987.

MONTEIRO, C. F.; VIANA, R. F. Formas de Inserção dos Trabalhadores da Indústria Automobilística uma Economia de Mercado Hierárquica: aproximações a partir do caso do cluster automotivo do Sul Fluminense. Latitude, 11, n. 2, 2018. 
MOREIRA, A. OMC: Setor automotivo mundial não integrou Brasil nas cadeias de valor. Valor Econômico, 17 Jul. 2017. Disponível em: http://www.valor.com.br/empresas/5041254/omc-setorautomotivo-mundial-nao-integrou-brasil-nas-cadeias-de-valor. Acesso em: 19 Jul. 2017.

MOREIRA, F. R. Proposta de melhoria de layout na gestão de logística reversa ao fornecedor em montadora de veículos situada na região metropolitana de Curitiba. 2014.

MORETZSOHN, L. Jaguar Land Rover abre primeira fábrica própria fora do Reino Unido. O Globo, 14/6/2016. Disponível em: https://oglobo.globo.com/economia/negocios/jaguar-land-rover-abre-primeirafabrica-propria-fora-do-reino-unido-19498756. Acesso em: 30/7/2018.

MORGAN, G. The Multinational as a Corporate Form: a critical contribution from organization studies. In: BAARS, G. e SPICER, A. (Ed.). The Corporation: a critical, multi-disciplinary handbook. Cambridge: Cambridge University Press, 2017. p. 248-256.

MTE. Relação Anual de Informações Sociais (RAIS). MTE. 2020.

NUNES, R. Nissan inaugura fábrica em Resende. A Tarde, 16/4/2014. Disponível em: http://atarde.uol.com.br/autos/noticias/nissan-inaugura-fabrica-em-resende-1584667. Acesso em: $30 / 7 / 2018$.

OICA. 2019 Production Statistics. BY-COUNTRY-2019.XLSX. International Organization of Motor Vehicle Manufacturers 2020.

PIERITZ, O. Concessionárias de Automóveis: estratégias competitivas e relações de dependência com montadoras. Revista de Negócios, 8, n. 4, 2007.

PIORE, M. J.; SABEL, C. F. The Second Industrial Divide: possibilities for prosperity. New York: Basic Books, 1984.

RAMALHO, J. R. Estado-Patrão e Luta Operária: o caso FNM. São Paulo: Editora Paz e Terra, 1989. $244 \mathrm{p}$.

RAMALHO, J. R. Novas conjunturas industriais e participação local em estratégias de desenvolvimento. Dados-Revista de Ciências Sociais, 48, n. 3, 2005.

RAMALHO, J. R. Indústria e desenvolvimento: efeitos da reinvenção de um território produtivo no Rio de Janeiro. Revista Pós Ciências Sociais, 12, n. 24, p. 117-142, 2015.

RAMALHO, J. R.; SANTANA, M. A. Flexibilidade à francesa: trabalhadores na Peugeot Citroën brasileira. Tempo social, 18, n. 1, p. 115-132, 2006a.

RAMAlHO, J. R.; SANTANA, M. A. Trabalho e Desenvolvimento Regional: efeitos sociais da indústria automobilística no Rio de Janeiro. Mauad Editora Ltda, 2006b.

RENAULT-NISSAN-MITSUBISHI. Alliance 2022: new plan targests annual synergies of $€ 10$ billion and forecasts unit sales of 14 million \& combined revenues of \$240 billion. Paris; Tóquio 2017.

RIATO, G. MAN Latin America renova PPE em Resende. Automotive Business, 1/12/2016. Disponível em: http://www.automotivebusiness.com.br/noticia/25018/man-latin-america-renova-ppe-em-resende. Acesso em: 30/7/2018.

RIECK, R. M.; DICKSON, K. E. A Model of Technology Strategy: practitioners' forum. Technology Analysis \& Strategic Management, 5, n. 4, p. 397-412, 1993.

SABBADINI, F. S.; VILLAVICENCIO, J. R. Estruturas em Rede das Organizações e Pólo Automotivo na região do Vale do Paraíba. Revista de Negócios, 11, n. 4, p. 119-129, 2007.

SANT'ANNA, Á. L. d. M. Fidelização do cliente: proposta de um modelo de referência para planejamento e avaliação de programas de fidelidade no setor de pós-venda: caso de uma concessionária de caminhões e ônibus. 2004.

SANTOS, E. S. A estratégia de financiamento da demanda na indústria automobilística-o caso das concessionárias da Ford em Salvador. 2005.

SANTOS, R. S. P. O Sul Fluminense em questão: o papel das redes sociopolíticas na promoção do desenvolvimento regional. In: RODRIGUES, I. J. e RAMALHO, J. R. (Ed.). Trabalho e sindicato em 
antigos e novos territórios produtivos: comparações entre o ABC paulista e o Sul Fluminense. São Paulo: Annablume, 2007. p. 89-118.

SANTOS, R. S. P. Redes de Produção Globais (RPGs): contribuições conceituais para a pesquisa em Ciências Sociais. Revista Pós Ciências Sociais, 8, n. 15, p. 127-142, 2011.

SANTOS, R. S. P. d. Relato da Visita Institucional à Fábrica da Jaguar Land Rover Brasil (JLR) em 27 de novembro de 2019. UFRJ. Rio de Janeiro, p. 22. 2019.

SANTOS, R. S. P.; MILANEZ, B. Estratégias corporativas no setor extrativo: uma agenda de pesquisa para as Ciências Sociais. Caderno Eletrônico de Ciências Sociais, 5, n. 1, p. 01-26, 2017.

SINACEG. Sindicato Nacional dos Cegonheiros. 2018. Disponível em: http://www.sinaceg.com.br/. Acesso em: 27/7/2018.

SINCODIV-RJ. Quem Somos. Rio de Janeiro, 2018. Disponível em: http://www.sincodivrj.com.br/quemsomos.php. Acesso em: 27/7/2018.

SMC. Hyundai Heavy Industries contratará 200 até fím do ano. 24 set. 2012. Disponível em: https://www.simec.com.br/?area=ver_fique_ligado\&id=4149\&titulo=hyundai-heavy-industriescontratara-200-ate-fim-do-ano. Acesso em: 6 dez. 2020.

SMSF. Boletim 9 de Novembro. Informativo do Sindicato dos Metalúrgicos do Sul Fluminense. SMSF. Volta Redonda: SMSF 2012.

SOUZA, M. A. d. Pós-venda em concessionárias líderes de vendas de veículos 0Km: uma análise das melhores práticas. 2017.

STURM, H. J. The Effects of Follow Sourcing on Local Suppliers: an exploratory study of the automotive industry in Brazil. Orientador: BAGANHA, G. S. M. M. P. 2017. 45 f. Dissertation (Professional Master) - Business Administration; Management, Instituto de Ensino e Pesquisa (INSPER); NOVA School of Business \& Economics, São Paulo; Lisboa.

TORRES, R. L. A indústria automobilística brasileira: uma análise da cadeia de valor. 2011.

TORRES, R. L.; CARIO, S. A. F. A governança da cadeia global de valor na indústria automobilística: um estudo de caso. Revista Econômica, 14, n. 1, 2013.

TREVIZAN, J. P. G. Melhoria contínua da qualidade no processo de pintura automotiva. 2013.

UNCTAD. Web table 19. The world's top 100 non-financial MNEs, ranked by foreign assets, 2019. WIR2020TAB19.XLSX. : UNCTAD 2020.

VOLKSWAGEN. Campanha interna marca nova era da Volkswagen Caminhões e Ônibus. 2017.

WALMRATH, L. L. Proteção ao Emprego e Renda em Tempos de Crise: o PPE na Man Latin America. Revista Habitus, 16, n. 1, p. 42-61, 2018.

WALMRATH, L. L. O Enraizamento Sociopolítico da Decisão de Investimento Locacional: a opção da Nissan por Resende (RJ). 2021. 243 f. (Mestrado) - Programa de Pós-Graduação em Sociologia e Antropologia (PPGSA), Universidade Federal do Rio de Janeiro (UFRJ), Rio de Janeiro.

ZHENG, C.; DI MILIA, L.; ROLFE, J.; BRETHERTON, P. Emerging Strategic People Management of Coalmines in Central Queensland. Management Research News, 30, n. 4, p. 302-313, 2007.

ZOTT, C.; AMIT, R. The Fit Between Product Market Strategy and Business Model: implications for firm performance. Strategic Management Journal, 29, n. 1, p. 1-26, 2008. 